\title{
WestVirginiaUniversity
}

THE RESEARCH REPOSITORY @ WVU

Graduate Theses, Dissertations, and Problem Reports

2004

\section{Identity development and empathy as related to creative activity participation}

Shana L. Blackshire

West Virginia University

Follow this and additional works at: https://researchrepository.wvu.edu/etd

\section{Recommended Citation}

Blackshire, Shana L., "Identity development and empathy as related to creative activity participation" (2004). Graduate Theses, Dissertations, and Problem Reports. 2027.

https://researchrepository.wvu.edu/etd/2027

This Thesis is protected by copyright and/or related rights. It has been brought to you by the The Research Repository @ WVU with permission from the rights-holder(s). You are free to use this Thesis in any way that is permitted by the copyright and related rights legislation that applies to your use. For other uses you must obtain permission from the rights-holder(s) directly, unless additional rights are indicated by a Creative Commons license in the record and/ or on the work itself. This Thesis has been accepted for inclusion in WVU Graduate Theses, Dissertations, and Problem Reports collection by an authorized administrator of The Research Repository @ WVU. For more information, please contact researchrepository@mail.wvu.edu. 


\title{
IDENTITY DEVELOPMENT AND EMPATHY AS RELATED TO CREATIVE ACTIVITY PARTICIPATION
}

\author{
By \\ Shana L. Blackshire

\begin{abstract}
A THESIS
Submitted to

The College of Agriculture, Forestry and Consumer Sciences

at

West Virginia University

In partial fulfillment of the requirements for the degree of

Master of Science

in Child Development and Family Studies
\end{abstract}

Carol A. Markstrom, Ph.D., Chair

Barbara G. Warash, Ed.D.

Dottie D. Rauch, M.Ed.

Morgantown, West Virginia

2004

Keywords: Adolescent, Identity, Empathy, Creative Activity 


\title{
ABSTRACT \\ Identity Development and Empathy as Related to Creative Activity Participation
}

\author{
Shana L. Blackshire
}

The focus of this study was the associations between identity, empathy as an emotional construct, and participation in creatively focused activities among adolescents in a largely rural population. A series of measures to assess identity status, the ego strength of fidelity, empathy, and level of participation in creative activities were administered to 212 male and 320 female adolescents in grades nine through eleven at public high schools in Appalachia. Analyses indicated that while the expected relationship between creative activity participation and identity was not statistically significant, gender may heavily influence that relationship as a mediating variable. Empathy, however, was found to be significantly related to creative activity involvement and to both identity status and the ego strength of fidelity. 
Dedicated to:

Rick, my support and occasional kick in the right direction during the moments of frustration. Now we can finally move forward with all those bright plans for the future.

You are my inspiration and my guide. I love you always. 


\section{ACKNOWLEDGEMENTS}

I want to express my most sincere appreciation to my advisor, Dr. Carol Markstrom, and my committee members, Dr. Barbara Warash and Mrs. Dottie Rauch for their patience with me in this very long process.

I would like to acknowledge my family, who has suffered long in my absence while I worked on this project. My parents, Bob and Jane Blackshire, my brother Charles, and my sisters Aurora and Veronica. Thanks to Chrys, who has been encouraging and supportive through this process when not everyone has been as understanding. Last but not least, thanks to Kati for keeping me sane by helping me take gaming breaks when necessary and sharing the computer ; ) 


\section{TABLE OF CONTENTS}

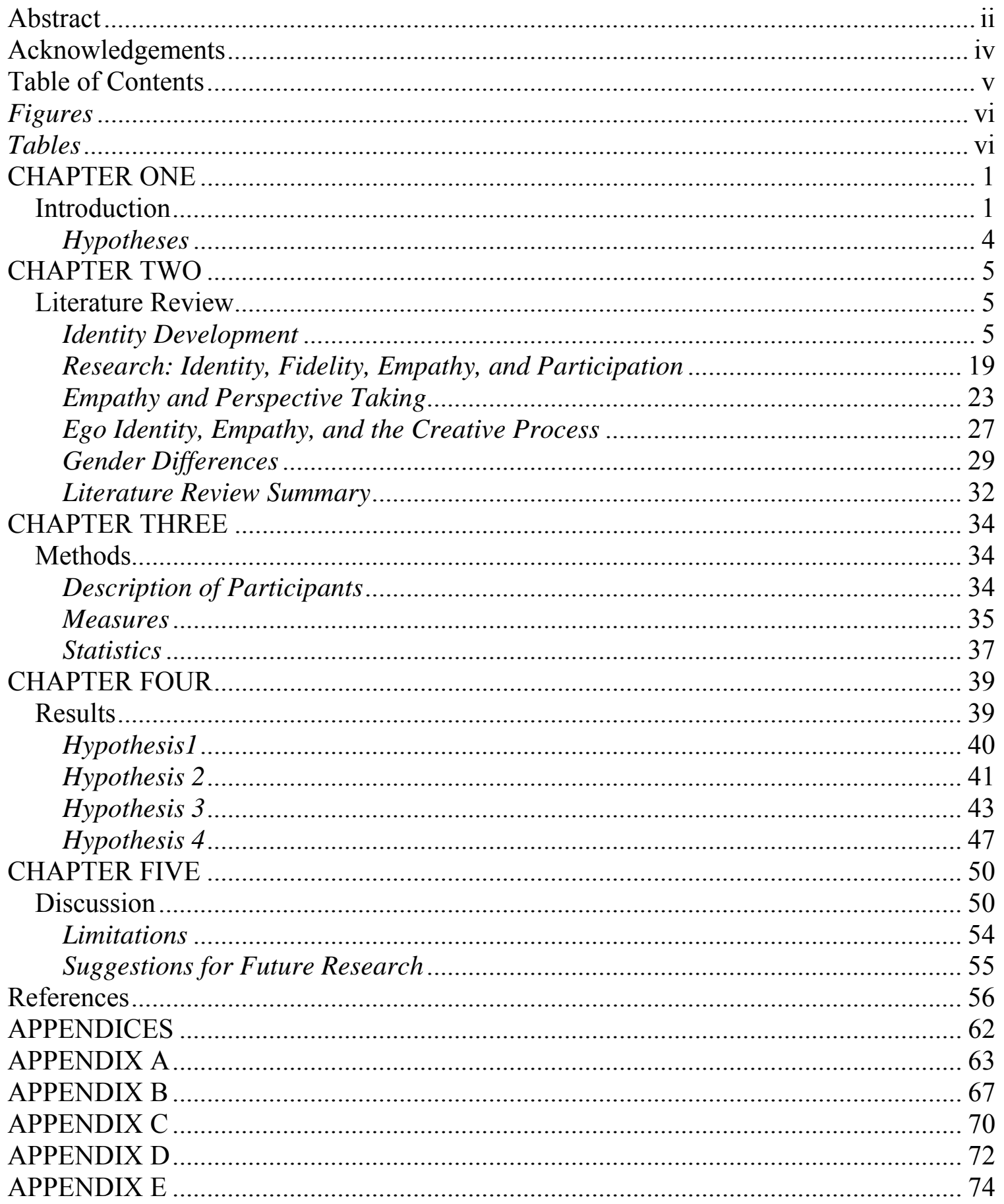




\section{LIST OF FIGURES AND TABLES}

\section{Figures}

Figure 1. Research model ...................................................................................... 4

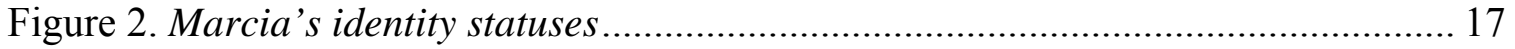

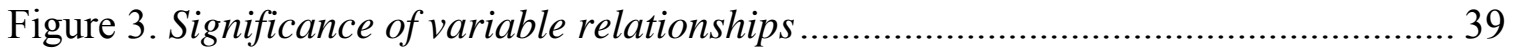

Figure 4. Mean moratorium scores by gender and creative involvement....................... 45

Figure 5. Mean diffusion scores by gender and creative involvement............................. 45

Figure 6. Mean fidelity scores by gender and creative involvement.............................. 47

Tables

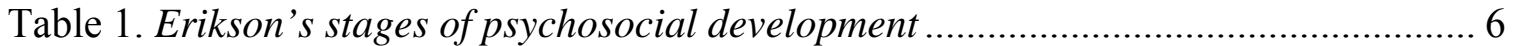

Table 2. Means of emapthy subscales by gender and creative involvement .................... 41

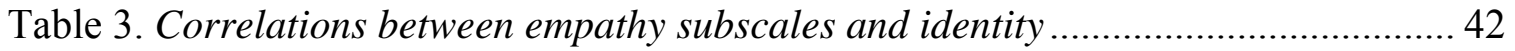

Table 4. Means of identity status subscales by gender.............................48

Table 5. Summary of regressions for variables predicting fidelity ................................. 48

Table 6. Summary of regressions forvariables predicting identity acheivement.............. 49 


\section{CHAPTER ONE}

Introduction

Adolescence is the period in life during which the most critical of Erikson's psychosocial developmental achievements, identity, is accomplished. It is the completion of this task that prepares the individual for true adult interaction socially and emotionally. A fully formed ego-identity is the awareness of self that provides a grounded emotional perspective from which one can view and interpret the goings-on of the world. This emotional grounding is of the utmost importance within the realm of human interaction and in understanding the feelings of others.

Empathy is the cognitive and emotional reaction to the observed experiences of another (Davis, 1983). It is among the most human of responses to be able to empathize with and understand another person's position and feelings. Many theorists, Erikson (1950) and Piaget among others, have noted that this advanced psychological phenomenon requires a certain level of cognitive and social-emotional development in order to take place. Adolescence is the time when these abilities come to the fore (as is true for aspects of identity) due to new cognitive prowess and new social situations (Piaget, Marcia). Because the ability to imagine non-concrete situations and to assume the perspective of others is considered essential to empathy, it is expected that empathy should be related to overall identity development.

The common perception has always been that artists (individuals involved in creative endeavors) are highly emotional people, but does a connection exist between empathy or identity achievement and the pursuit of artistic endeavors? One might speculate that if such a connection does exist, it might be that those who feel moved to 
artistic expression are seeking a means of self-expression and, consequently, are exploring their own identities and learning more about the feelings experienced by others. In such processes, do creative adolescents learn more about their own identity and their emotional interaction than those who do not?

Statement of the Problem

Adolescence is the period of life wherein we first become truly capable of advanced growth in areas of self-understanding. It is because of this newfound ability for self-analysis that the development of all aspects of identity, including caring and empathy, is heightened during adolescence. Those individuals pursuing creative endeavors have been noted to be more sensitive to emotion and possess a greater understanding of self (Waterman \& Archer, 1979). Waterman (1990) even suggested that personal expressiveness (in terms of an intrinsic, self-motivated enjoyment of an activity), as might be seen in creative pursuits such as poetry or music, is an integral part of a fully-realized identity. Because of this observed link between self-awareness and creative pursuit, it would be worthwhile to examine the possibility that such a link would extend to maturity in identity development. It could be of great help to developing adolescents if they can be directed toward activities that encourage positive psychological development. Additionally, it is important to identify those adolescents who are more advanced as well as those who may need attention by taking note of their interests in various activities.

Purpose of this Study

Marcia (2002) argued that as adults and as psychotherapists, it is necessary to the goal of helping to "grow" stronger and healthier adolescents that we come to understand 
the processes by which that growth occurs (p. 199). By learning how psychological growth processes occur and what may affect them, we can hope to enable adolescents to flourish to their fullest potential. The purpose of this study was to assess whether relationships exist between the developmental areas of ego identity status and empathic ability and participation in creatively involved scholastic activities. The formation of one's ego identity requires the ability to see oneself and society's expectations from the outside (Adams, 1976; Erikson, 1997). Thus it might be concluded that those who are better able to understand the feelings and thoughts of others (greater empathy) will engage in greater comparison of their own thoughts and feelings to those of others and subsequently are more advanced in ego identity development.

It also was expected that those adolescents who are motivated to seek out some form of artistic self-expression will utilize this opportunity for expression to explore their own feelings and the feelings of others around them, leading creatively involved adolescents to greater development of their own ego identity and greater empathy for others. It may be speculated that those adolescents who possess greater empathic ability and are more advanced in their self-exploration would seek out these activities as a means of expression. Or, alternately, it may be that involvement in creative activities fosters growth in these areas. Determining the direction of these relationships or their causality would require longitudinal data, which were not assessed in this study. Gender differences in the measure of each variable and any correlations were assessed due to the fact that previous data has illustrated gender differences in identity (Lewis, 2003), empathy (Eisenberg, Miller, Shell, McNalley \& Shea, 1991), perspective taking 
(Eisenberg, Zhou \& Koller, 2001), and extracurricular involvement (Eccles \& Barber,

1999).

\section{Hypotheses}

This study examined the following relationships:

1. Those adolescents who score higher on a measure of empathy will be more likely to participate in creatively involved extracurricular activities.

2. Adolescents who score higher on a measure of empathy will be more advanced in identity development.

3. Adolescents who participate in creatively involved extracurricular activities will score higher on measures of identity development.

4. Identity development will be most advanced in those adolescents who both exhibit higher empathy and are involved in creatively centered extracurricular activities.

Gender was included in all of the above analyses because it was expected to independently impact each of the other variables. Females were expected to have higher scores on the measure of empathy and on measures of identity and the ego strength of fidelity. More females were expected to participate in creatively centered extracurricular activities.

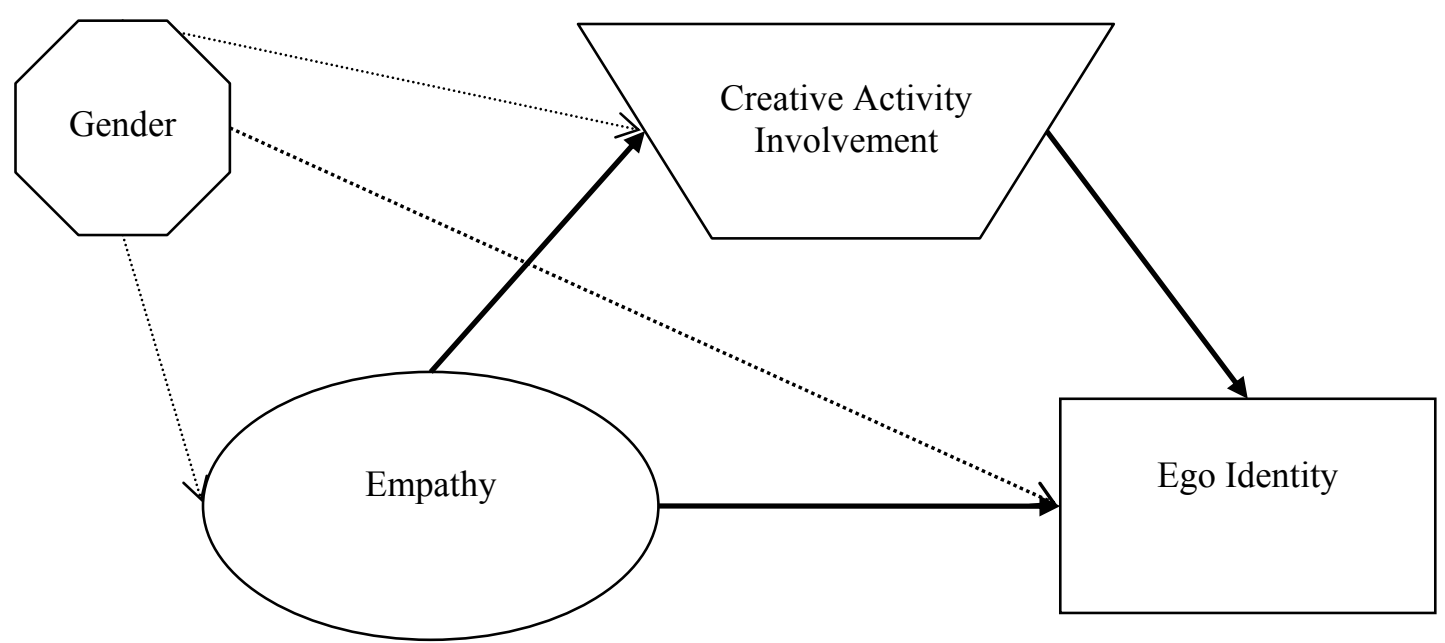

Figure 1. Adolescents high in empathy will be more motivated to be involved in creative activities. Empathy will also be directly related to ego identity status, but identity should be more advanced among those who participate in creative activities. Females should exhibit greater empathy, greater involvement in creative activities, and more advanced identity status. 


\section{CHAPTER TWO}

Literature Review

The development of identity during adolescence has been studied in some breadth since Erikson's (1950) formulation of a theory describing the process by which identity comes to be such an important factor in life. The following literature review examines identity from the perspectives of Erikson and Marcia and some of the relevant literature on identity development. Empathy is discussed in terms of how it is viewed/measured by the psychological community and in what ways it may be related to both identity development and creative activities.

\section{Identity Development}

For Erikson, all aspects of psychosocial development are to some extent intertwined at each stage of development, but each aspect has its own time of ascendancy at some period of life, which represents a crisis, or a 'turning point' for the individual. With respect to each particular aspect of development, the individual faces either potential for growth and future strength (if the crisis is resolved successfully), or a vulnerability for maladjustment and future stagnation (if the crisis is not resolved) (Damon, 1983, p. 87).

Erikson's $(1950,1968,1997)$ psychosocial theory of human development is rooted in the premise of stage-wise growth. Expanding on the ideas of previous generations of psychologists (S. Freud, A Freud, Piaget, etc.); Erikson devised a set of eight stages of psychosocial development (as opposed to the psychosexual stages of Freud) that incorporate aspects of physical, cognitive, psychological, and social growth in the human life cycle. Within each stage, an emotional crisis (or developmental task) 
must be faced, wherein successful resolution of the crisis leaves the individual better prepared for handling the next crisis and other tasks in their life. An unsuccessful end to the crisis will likely lead to difficulties in future developmental tasks. Failure to resolve the crisis does not, however, indicate the certain failure of the individual to successfully complete any further development. Erikson believed that throughout the lifespan, all aspects of development were present to some degree, but each has its period of ascendancy during its own crisis stage. Therefore, development of any psychosocial skill could occur during another crisis period, but the greatest potential for development of a certain strength is during that stage. In attempting to fully describe the developmental changes taking place at each stage, Erikson also included what he proposed to be the basic emotional strengths gained by successful completion of each developmental task. There are eight ego-strengths, one new basic emotional skill learned with each crisis resolution. Additionally, there are eight antipathies that can be the emotional shortcomings of those who fail to complete a certain developmental task. (Erikson, 1997). Table 1 outlines the eight stages of psychosocial development and their associated ego strengths.

Erikson describes the stage-wise progression of psychosocial development by borrowing a term from the field of embryology, specifically, epigenesis. As described by Erikson (1997), the development of the human embryo happens in stages. Generally each part of the body has a designated time during embryonic development for its budding and growth. If the development of that body part is interrupted by some outside force or the growth of another organ, it will be forever modified by the loss of supremacy to another organ. The under-developed organ will most likely then affect the future 
growth and stability of the entire organism, as the health of the organism depends on the proper interaction of all the organs together. Epigenesis in terms of psychosocial development, then, also describes the progression of human development—one part of the psyche following another in ascendance, building on what is already there. Similarly, if one stage of psychological development is cut short or not completed, the individual will continue to grow, but the health of the individual on the whole will be affected by the underdeveloped portion of their psyche.

Table 1.

Erikson's Stages of Psychosocial Development

\begin{tabular}{|l|c|c|}
\hline \multicolumn{1}{|c|}{ Stages } & Psychosocial Crises & Basic Strengths \\
\hline I Infancy & $\begin{array}{c}\text { Basic Trust vs. Basic } \\
\text { Mistrust }\end{array}$ & Hope \\
\hline II Early Childhood & $\begin{array}{c}\text { Autonomy vs. Shame, } \\
\text { Doubt }\end{array}$ & Will \\
\hline III Play Age & Initiative vs. Guilt & Purpose \\
\hline IV School Age & Industry vs. Inferiority & Competence \\
\hline V Adolescence & Identity vs. Identity \\
Confusion
\end{tabular}

Note. Adapted from Erikson (1997) pp.32-33. 
Erikson's stages are named for the conflict or crisis faced in each one. Further, while the stages are ordered and do correlate to certain age-ranges, they are less agedetermined than maturity- or task-determined. In infancy, the conflict faced by the child is that of Trust vs. Mistrust. The infant must learn to trust that his environment is saferesolution of the crisis leads to a basic trust in the world around him while failure to resolve this crisis leads to mistrust of others, the self, and the world in general. Ainsworth's many $(1962,1967,1970$, etc.) classic studies of infants in the 'strange situation' and regarding separation anxiety could be used as an example of this trust or mistrust in the world. Ainsworth placed infants in unfamiliar situations where their mother would leave the room and/or the infant would be approached by a stranger to illustrate different levels of infant attachment to their caregiver. The infants' behaviors varied in whether they would explore the room, respond to or avoid strangers, and welcome or reject the return of their caregiver. Ainsworth's studies on infant attachment illustrate that some infants are more trusting of the world (assume mother will return, the room is safe to play in, strangers are not necessarily a danger) while others show a marked mistrust of the environment and their caregivers.

In the toddler years of early childhood, the struggle for independence is paramount. The crisis of Autonomy vs. Shame and Doubt is most often illustrated through the issue of toilet-training. Erikson (1950) discussed the unusual dilemmas presented by a toddler's dual desires to hold on and let go as they discover the new abilities to retain or eliminate urine and feces. Erikson also noted that the uncertainty of this stage extends to nearly all areas of the child's interaction - they may want to be cuddled and held one minute, but push the parent away in the next, or clutch a favorite 
toy all day long, only to throw it out the window later. However, toilet training is the greatest test of this new ability to retain or eliminate, and there is in Western culture a fair amount of pressure on the child to learn to control bodily functions. Erikson (1950) warned that excessively rigid training can take away the child's feeling that he is exercising this new task of his own free will and can lead the child to either revert to more infantile behaviors (for instance, thumb sucking) or to pretend autonomy by using their urine or feces as ammunition. If the child is able to feel that they have successfully mastered the ability to hold on or let go of their own accord, they will go on to develop healthy attitudes towards the events of their life and an overall sense of autonomy. A child who is shamed into controlling his body and behavior will turn these abilities into destructive forces against the outside world or be filled with self-doubt such that he grows to fear constant persecutions from without and within. Thus, successful completion of the stage of Autonomy vs. Shame and Doubt is paramount in the development of an individual's psyche. Adolescence is the only other stage of human development in which so many changes affect the individual's physical and psychological well-being (Berk, 1994).

During what Erikson calls the play years of early childhood, the crisis to be resolved is that of Initiative vs. Guilt. Successful resolution of this crisis results in selfassurance in one's abilities to act to complete tasks physically and intellectually. The development of initiative is important to social and scholastic achievement; failure to resolve this crisis can leave the child without the ability to confidently interact with peers and approach new challenges. Such lack of initiative can lead to withdrawal from many sorts of activities crucial to social and academic acceptance. A child who lacks initiative 
may never discover potential to excel at athletics or art or academics due to fear that participation will lead to failure.

The school years bring the conflict of Industry vs. Inferiority wherein a child must master the ability to remain focused on a task through its completion and produce a result. The skills learned in this stage are especially important in formal education so that the child can complete school assignments, follow rules, and feel worthy of and equal to his/her peers. This is also the time when the child will be entering the period of latency in his psychosexual development, forgetting for a time the familial and personal involvements, focusing on learning to be productive and to provide for his future. Difficulty in mastering the emotional lessons of this stage can lead to feelings of inferiority, causing further problems as the child matures and feels himself to be less than equal to his peers and the tasks that must be completed in future stages (Erikson, 1950). A child who feels inferior may shy away from participating in activities or feign a certain amount of confidence in his/her ability by boasting or attempting to bully other children when faced with a task of which they are unsure.

Identity vs. Role Confusion, the most crucial stage of development comes as puberty begins. The child has now become an adolescent who is maturing physically and mentally. The adolescent is now aware of him/herself in a different light, they are able to take another's perspective and see how others view them. The cognitive advancements taking place allow the beginnings of formal thought (Piaget \& Inhelder, 1969) and perspective taking (Eisenberg et al., 1991). Piaget and Inhelder (1969) described adolescence as a period where, in terms of cognitive development, the individual experiences a state of, "liberation from the concrete in favor of interest oriented toward 
the non-present and the future" (p.130). This new focus on ideals and relationships is dependent upon a transformation in thought allowing the adolescent to consider hypothetical situations separate from the concrete here and now. The adolescent's new cognitive ability to perceive the realm of possibility for the world around them leads to the emotional task of assessing oneself.

Erikson's fifth stage of Identity vs. Role confusion is the most important because it is during this time of physical, cognitive, and emotional growth that the individual begins to solidify their concept of self - to form their identity (Erikson, 1950). The completion of this task is central in many ways to the future health of the adult; understanding oneself with respect to personal and professional interests, morality, intellect, and sexuality will shape how one chooses to pursue life goals.

Erikson (1950) characterizes this stage as a time when, after several years of relatively little change in their inner world, the adolescent's sense of continuity is disrupted by the physical and mental changes they are experiencing. The adolescent is utilizing his or her new skills to create a new perception of the world around them. This re-evaluation is likely to include global, moral, or religious issues such as political alignment, or environmental concerns. However, the issues most likely to be critically examined hit closer to home. School and home environments are assessed, as are personal relationships with parents, friends, family, and authorities.

Cognitive changes taking place allow the adolescent to view themselves and their relationships from the perspective of a third party, "What does my relationship with my mom look like to another person?", but still with the limited understanding of an individual lacking much interpersonal experience, “My friend's mom lets him stay out 
late at night, therefore my mom treats me badly." Such conclusions can result in the difficult period of "storm and stress" that we have come to identify with adolescence. Adolescents often seem to make adversaries of their parents and other adults that may try to help them in their task.

Marcia (2002) suggests that such antagonistic encounters with adolescents may arise when the adolescent's internal struggle over some issue becomes externalized. It is the adult's job to observe and acknowledge the struggle without taking sides on the issue, preventing the adolescent from automatically taking up the opposite side of the issue and making the adult an antagonist. The new insights that accompany the cognitive development of adolescence without the guidance of wisdom leads adolescents to make poor choices regarding the situations they choose to put themselves into. It is the task of the adults guiding each child to help them through this period by providing advice when needed, and allowing room for exploration as well. Such careful navigation of adolescence is important because failure to complete the task of identity formation in adolescence will make interaction in adult situations more challenging and successful resolution of future crises more difficult.

As late adolescence comes to an end, the individual will emerge with a stable sense of who they are and what they want from life. This newfound self-knowledge leads them to pursue life-goals such as education, career, and intimate relationships.

"The strength acquired at any stage is tested by the necessity to transcend it in such a way that the individual can take chances in the next stage with what was most vulnerably precious in the previous one. Thus, the young adult, emerging from the search for and the insistence on identity, is eager 
and willing to fuse his identity with that of others." (Erikson, 1950,

Erikson explained that, only after the completion of his own identity formation, is the young adult ready for intimacy, which is defined by Erikson (1950) as... "the capacity to commit [oneself] to concrete affiliations and partnerships and to develop the ethical strength to abide by such commitments, even though they may call for significant sacrifices and compromises”( p.263). Such a demanding level of interaction is not a task most adolescents are capable of and so most sexual interactions prior to completion of ego-identity and the ability to commit are "of the identity-searching kind, or [are] dominated by phallic or vaginal strivings which make of sex-life a kind of genital combat." (Erikson, 1950, p. 264). Erikson believed that truly intimate relationship cannot be formed until the next stage, in adulthood, wherein intimacy is really explored.

Socio-emotional development does not end once we achieve adulthood. Young adults enter the stage Erikson calls Intimacy vs. Isolation, where the central developmental task is to learn to form lasting, committed relationships with others. One must learn to maintain the newly conceived ego throughout experiences of friendship, sexual encounters, competition, and combat (Erikson, 1950). The danger here is that the individual may feel so unsure of their ability to 'safely' interact with others on such intimate levels that they may withdraw from those experiences altogether, leading to feelings of isolation and self-absorption. Genital love (sexually committed relationship) is the primary concern during this stage of life during which most individuals pair off into couples. 
As individuals grow into more mature adults, the crisis of Generativity vs. Stagnation comes to the fore. Now, as full-fledged adults, society insists that its members must utilize all of the lessons learned in childhood and adolescence to be productive and creative members of society. Generativity, as a concept, encompasses both the procreative and social functions of bringing children into the world and rearing them, but also productivity in work and sharing knowledge and personal gifts with those around us. The challenge in this stage of life is that if one fails to experience the personal enrichment that comes of sharing intimately and productively with others, a sense of stagnation and personal impoverishment can ensue. To soothe the uncomfortable strain in their life, one can regress to (or retain) an "obsessive need for pseudo-intimacy" and exhibit behaviors that seem to fit the popular-culture notion of a mid-life crisis (Erikson, 1950). This behavior can be very self-indulgent and childish, focusing primarily on individualism rather than social productivity. Erikson (1950) points out exactly how important early developmental tasks are in successful navigation of adulthood in noting that many young parents, while they may have reproduced, fail to achieve generativity due to failures in the very basic first task of Trust vs. Mistrust. Such adults may have developed their personalities too much around themselves and lack an essential faith in humanity and the inherent value of a child to the society.

As humans grow to old age, Erikson's theory recognizes that they do not cease to grow as individuals or to participate as members of society. The emotional crisis faced in late adulthood is that of Integrity vs. Despair. The final fruition of the cumulative knowledge and experiences of life's previous stages is what Erikson calls ego integritya phrase by which he seems to describe a person accepting of and even appreciative of 
life as it is. A person who has achieved such ego integration feels satisfied and justified in the life they have lived and has no fear of its conclusion. They have accepted their role in the society as both leader and follower, developed a love of humanity beyond the self, and a sense of order and purpose to the world. An individual who has not achieved ego integration suffers despair and disgust for the life they lived and the life goals not achieved. Because they feel that they have not been successful as a human being, they feel life is too short. The time remaining is not enough to remedy the mistakes of the past, nor enough to start again and achieve the missed integrity in other ways. The final stage in Erikson's theory of psychosocial development truly represents the full extent of what is accomplished throughout life.

The epigenetic development of human psychological and social well-being illustrates how important each of the previous stages is. Failure to completely develop any of the skills along the path will likely lead to a dissatisfied existence full of regrets toward the end of life. One cannot 'make up' lost time in physical or psychological development - once the time of ascendance for an organ or psychological task is passed, future growth in that area can occur, but will never again be dominant to other developmental processes. To bring the process full circle, Erikson (1950) notes that Webster's Dictionary describes trust (the first of the ego values) as, "the assured reliance on another's integrity" (p. 269). Humans are social creatures and so much of what each person learns as a child is dependent upon what examples are set by adults. Erikson then rephrases Webster's wording to more precisely describe the relationships that are shared, “...healthy children will not fear life if their elders have integrity enough not to fear death" (p. 269). 


\section{Development and Validation of Ego-Identity Status}

Developmental psychologist James Marcia (1966) narrowed in on that crucial period of adolescent development and examined how exactly the formation of identity takes place, specifically, what does it look like in progress? In doing so, Marcia took Erikson's broad theory one step further and separated the individual crisis of Identity vs. Identity Confusion into four distinct stages along the process of actually sorting out one's identity. Marcia (1996) postulated that identity is not dealt with as its own separate crisis until late adolescence because it is not until then that all the necessary components are in place (cognitive reasoning ability, mature physical state, developed sexuality, social expectations). A child of a younger age would not have acquired the mental and social sophistication, or the new physical aspects to question their own feelings about themselves or their place in society.

According to Marcia's (1966) theory, there are four different states of identity development. Rather than a stage-wise progression, the identity status exhibited by an individual is more dependant on whether they have made certain decisions about their future path in life and on whether they have spent time working out who they are and who they want to be. The four stages are identity diffusion, foreclosure, moratorium, and identity achievement (see Figure 2).

Identity diffusion is the pre-crisis stage - the adolescent has no concrete sense of self and no plan for their future or career, but is not in turmoil over these decisions. The individual in identity diffusion simply has not given much thought to their current or future place in society. This is typical of most individuals in early adolescence. Most teens in middle or junior high school are likely to be far more worried with present 
concerns than with what kind of person they would like to become and what may lie ahead in their future. Eventually, however, they will begin to make a more critical analysis of their academic, social, and personal emotional situations and begin experimenting with different possibilities.

Foreclosure is also pre-crisis, and can go on for a great many years. According to Marcia (2002) foreclosure is the most common stage from which adolescents begin their journey toward identity achievement. This individual has not spent time thinking about who they are and where to go in life, but their decisions have already been made. The adolescent or adult in a state of identity foreclosure has already decided on a life path, career, and educational choice (Marcia, 1966). The classic example is the high school or college student decided on medical school because their parents want a doctor in the family. The adolescent likely was never truly consulted and did not even considered if it is what they want. Though some pass through this stage more quickly than others, it may be many years down the road when this individual finally discovers that he or she would rather be an artist. Such a radical change in outlook might result in either a very unhappy doctor or a major upheaval in their career and family life.

\begin{tabular}{|l|l|l|}
\hline & $\begin{array}{l}\text { Have } \\
\text { experienced } \\
\text { crisis }\end{array}$ & $\begin{array}{l}\text { Have not } \\
\text { experienced } \\
\text { crisis }\end{array}$ \\
\hline $\begin{array}{l}\text { Committed } \\
\text { to future } \\
\text { path }\end{array}$ & $\begin{array}{l}\text { Identity } \\
\text { Achieved }\end{array}$ & Foreclosed \\
\hline $\begin{array}{l}\text { Not } \\
\text { committed } \\
\text { to future } \\
\text { path }\end{array}$ & Moratorium & $\begin{array}{c}\text { Identity } \\
\text { Diffusion }\end{array}$ \\
\hline
\end{tabular}

Figure 2. A model of Marcia's stages of identity development. (As adapted from Carlson \& Buskist, 1997, p. 401) 
Moratorium is in the midst of the crisis - this is when the adolescent is trying to figure out who they are, what are their personal goals, values, etc. They have struggled some over who they are as a person, but have not yet emerged with an answer. During moratorium the individual may 'try on' many different roles. They may adopt different manners of dress or speech, or most notorious among college students_-pursue several different possible career paths, changing one's college major once, twice, or more times.

The final stage is identity achievement. The individual with achieved identity status has experimented with different ideas about their personal, political, social, and ethical convictions and has some idea of where they want to take their life. Having emerged from the struggle to find self, the adolescent now is competent to make conscious choices about their future and is mature in their interpersonal relationships.

According to Marcia (2002), identity is a fourth personality structure that emerges in adolescence (the three other personality structures recognized in psychoanalytic theory are ego, self, and superego). This is why adolescence and the crisis of finding one's identity is so important to psychosocial theory. The crisis of identity occurs during adolescence because this is the first time in the lifespan when all of the necessary tools are in place. It is also, socially, the first time such introspection and outward analysis are really necessary for the child to get along in the world. An individual's physical, sexual, cognitive, and moral development do not reach the level of maturity that allow for dealing with issues of identity until all these aspects are fully or nearly fully developed. There is also the social pressure for the adolescent to start thinking about how he will fulfill the expected roles of worker, parent, and citizen. Identity fulfillment requires contemplation of life's choices and in order for an individual to commit to an identity, 
they must commit to an idea of self regarding occupation, religion, political and social beliefs, and also interpersonal and social values.

\section{Research: Identity, Fidelity, Empathy, and Participation}

Research on identity development has taken many paths, exploring the possible associations to nearly every aspect of human existence, for it is our experiences in the world which, in part, shape who we become as individuals. Advanced identity development has been associated with a multitude of positive outcomes for adolescents, including better academic achievement and further progress in college, greater levels of community involvement, extracurricular involvement, future citizenship responsibility, and greater levels of personal intimacy (Fitch \& Adams, 1983; Glanville, 1999; Lange \& Byrd, 2002; Neuber \& Genthner, 1977; Streitmatter, 1989; Waterman \& Waterman, 1972). Lange and Byrd (2002) cite that identity development is one of the most important factors determining a student's academic success and those students whom exhibit more advanced identity development are better judges of their predicted level of success at academic tasks. Research has also linked identity to a more mature understanding of intimacy. Fitch and Adams' (1983) longitudinal study found that both moratorium and achievement groups of college males and females experienced deeper intimacy. Erikson (1950) stated that having a sense of self was crucial to being able to engage in true intimacy with another person; how could a person share him/herself with another if he or she does not know who he/she is?

Relative to this study are the areas of empathy and perspective taking and how they may be related to identity development. Research on such topics has been somewhat sparse, but a few investigations have targeted connections between identity 
development and the cognitive-emotive processes of perspective taking and empathy. Perspective taking (the ability to put oneself into another's shoes) is considered an integral cognitive part of empathy, but it may be an important part of learning about the self as well. Enirght and Deist (1979) argued that social perspective taking, which is described as the understanding of the self from the viewpoints of other individuals, groups, and society, is a more precise description of what Erikson (1968, as cited by Enright \& Deist) called the 'awareness of all possibilities' which leads to identity formation. In an experimental study assessing perspective-taking training strategies for their effectiveness at promoting identity development, Markstrom-Adams, Ascione, Braegger, and Adams (1993) found those subjects who had undergone perspective-taking training to be advanced in ideological achievement. Lindsay (1995) found that perspective taking was a strong predictor of self-esteem, which has long been associated with identity (Marcia, 1966). Successful identity achievement seems to be dependent on an accurate perspective of the self and the world at large. Piaget (1969) observed in his writings that only through growth in the social arena leading to mutual respect (understanding) with others can individual autonomy be developed.

A healthier emotional state overall has been associated with advanced identity development in adolescents. Adams, Abraham and Markstrom (1987) conducted a series of studies linking advanced identity development to lessened self-consciousness in adolescents. Among their findings were that identity achievement was associated with decreased self-consciousness, a result they interpreted to indicate that the identity discovery process is necessary to a sense of satisfaction and confidence of self as well as reduced anxiety or uneasiness when one is the center of others' attention. Similarly, self- 
esteem has been linked to identity achievement status. In his original discussion of a measure to assess the four ego identity statuses, Marcia (1966) used self-esteem as an indicator of identity achievement. Subjects who scored in the achievement status were less likely to give up on a stressful concept attainment task and less vulnerable to negative information concerning their self-esteem.

Ego strengths are what Erikson describes as the values learned or 'strengths' gained from a successful resolution of each particular crisis stage. Fidelity is the ego strength Erikson associated with the adolescent crisis of identity vs. identity confusion. Along with the endeavor to discover self, the search for fidelity, both internal and external, is what Erikson says leads youths to join organized experiences (1968). Involvement in youth activities (as social groups and organizations) promotes development of the ego strength fidelity (Erikson, 1968). Greater development of ego strengths through crisis resolution leads to greater likelihood of success in handling later crisis stages, which leads to better overall identity development and all the positive outcomes associated with it. Markstrom and Kalmanir (2000) showed that the ego strengths of fidelity and love were indeed predicted for subjects that showed greater identity and intimacy respectively, validating that, true to Erikson's theory, we can expect to see ascendance of the associated ego strength where each developmental crisis has been successfully dealt with.

Participation in extracurricular or other organized activities is important to youth development, especially to identity, but also self-esteem, academic progress, emotional well-being, etc. (Dworkin, Larson \& Hansen, 2003; Eccles \& Barber, 1999; Guest \& Schneider, 2003 ). Many times in his discussions of the identity crisis, Erikson (1968) 
noted the importance of all different sorts of youth organizations because they provide a social outlet for young people's search for ideals and for a focus for their developing sense of fidelity. Eccles and Barber (1999) and Barber, Eccles, and Stone (2001) both examined benefits and risks associated with participation in high school activities. Both studies did find that some risks were actually increased by participation in certain activities; alcohol use was greater among adolescents involved in sports, and performing arts participants were more likely to experience future emotional distress. However, overall participation in extracurriculars led to further educational achievement and better occupational placement. A study by Manners and Smart (1995) tested moral and identity development among high school juniors. While the study failed to find connections between identity and musical groups, it did confirm that students who participated in any form of organized activity were lower in interpersonal diffusion and ideological moratorium than their classmates who did not participate in any kind of activity. The same study also found higher levels of ideological identity achievement and lower levels of diffusion and moratorium among members of school clubs. Athletic involvement seemed to be the one negative association, as males involved in sports especially were found to be more stunted in their psychological development (foreclosure status).

Identity development is such a complex process that nearly all social, personal, and educational aspects of an individual's life will shape how the path to self-discovery is traveled. Tying in cognitive and emotional abilities as well as life experiences, such as school and community involvement, is one step toward a better understanding of the human psyche as a whole. Erikson's theory is one of psychosocial development, intended to examine and explain growth of the human psyche in the context of its social 
environment. Through careful analysis of both psyche and environment, we may come to a deeper understanding of the complexities that make up one's sense of self, one's identity, and help promote positive development of identity for others.

\section{Empathy and Perspective Taking}

In taking note of both the cognitive and emotive parts of empathic feeling, Davis (1983) discussed the necessarily complex reality of measuring human emotion, especially that of human empathy. Empathy has been studied over the years as both a cognitive (Dymond, 1949) and emotional (Stotland, 1969) component of human interaction due to differing theorists' opinions of the process. Perspective taking (the ability to see another's point of view) is an integral component of empathy (Davis, 1983) and the ability to have satisfying adult relationships (Franzoi, Davis, \& Young, 1985). Because the ability to put oneself in another's shoes is, according to cognitive theorists (Piaget \& Inhelder, 1969), one that must be developed as the brain and thought processes mature, empathy has been examined as a cognitive trait. Other branches of theory (Eriksonian) have suggested that empathy is an emotional skill learned after much practice in the realm of human interaction. Both assumptions presume that one's understanding of and abilities regarding empathy would increase with maturity. More recently, researchers (Davis, 1983; Franzoi, Davis, \& Young, 1985) have begun to think of empathy as a concept encompassing a wider range of abilities, both cognitive and emotional.

Davis (1983) includes four different areas of emotional and cognitive behavior in his measure of overall empathy. Perspective taking (PT) is the most cognitively centered portion of empathic behavior. Perspective taking would seem related to the new development of formal thought that occurs in early adolescence (Piaget \& Inhelder, 
1969), allowing the formulation of propositional situations and analysis of what one imagines another person feels. Each of the other areas of empathic behavior is in some way dependent upon an individual's ability to perceive the position and feelings of others- to see another's perspective.

Fantasy (FS) is a tendency to extend one's own emotions to another (fictional) person and become emotionally involved in that person's situation. Davis notes that this skill is often exhibited in ways such as crying at movies or books when some tragic fate befalls the heroine. Empathic concern (EC) is the tendency to express sympathy for another's well-being and is thought to be important in forming satisfactory and rewarding social relationships. People are likely to be more responsive and caring if they feel someone understands them and will reciprocate their concern more frequently. Personal distress (PD) is the more negatively associated portion of empathic ability. It indicates that the individual has the cognitive ability to imagine what others might feel, but utilizes that skill to imagine what others think of them or to focus on how they are personally feeling about a particular scenario (Davis, 1983). This type of empathic thinking is best illustrated in the phenomenon of the imaginary audience, where an egocentric adolescent believes that they are under constant scrutiny, always on stage (Dusek, 1996).

Examining adolescent development from different psychological perspectives shows how intricately woven the fabric of the human psyche actually is. Tying in to other aspects of development, we assume that empathy is an ability which undergoes a great change during adolescence. As adolescence begins, cognitive theory (Piaget \& Inhelder, 1969) holds that the beginnings of formal thought are taking shape, allowing the youth to begin to understand the world from a perspective not his own. With the dawning of this 
realization, Erikson's (1968) ego development theory states that the youth should begin to examine how these views may converge or contrast, leading to critical analysis of many other social situations and the beginning of the identity vs. identity confusion stage of ego development. Logically, delving in such a way into one's personal understanding of the world and one's relation to others should increase empathic understanding and concern for others.

In fact, Dymond, Hughes, and Raabe (1952) examined the changes in empathy according to age among children. They found that between the ages of seven and eleven, there was a marked increase in measured level of empathy. Eisenberg, Miller, Shell, McNalley and Shea (1991) examined several aspects of prosocial moral reasoning in children and adolescents in a longitudinal study spanning eleven years. In this study, empathy was understood as a component of moral reasoning for adolescents because adolescent cognitive abilities and perspective taking are what allow for the sort of moral reasoning that leads to prosocial behavior. They suggested that empathy and sympathy may stimulate the development of moral principles. Eisenberg et al. (1991) found that empathy and perspective taking did increase with age in adolescents, leading to more advanced moral reasoning and prosocial behavior, especially among girls.

Previous research on empathy has examined the possible relationships with other aspects of psychological development. Hawkes and Egbert (1954) measured empathic ability against a test of personal values. Their findings indicated that the values most highly associated with empathy were those involving group and social interaction. As noted above, Eisenberg et al. (1991) included empathy and perspective taking in a study of moral reasoning and prosocial behaviors, concluding that "prosocial moral reasoning, 
prosocial behavior, and empathy/sympathy and perspective taking were interrelated in theoretically meaningful ways..." (p. 857). Eisenberg et al. (1991) suggested that empathy and perspective taking may be linked to the change in adolescence from a moral system of direct reciprocity to a higher, more selfless mode of moral reasoning. Establishing a moral code for oneself (i.e., what do I believe in) is an essential part of developing a sense of self, an identity. Following this reasoning, empathy and identity scores should be higher for adolescents participating in group activities, like many extracurricular activities at school, but especially so for those participating in more intuitive and emotive activities that challenge adolescents to explore their feelings about others and self.

Such findings support Piaget's (1969) assertion that the preadolescent's new focus on social interaction is due to the change in thought processes that allow for hypothetical and theoretical scenarios. Erikson's epigenetic principle (1997) also states that psychological development and ego identity development are dependant on physical/cognitive maturity and reasoning. It would seem, from a comparative analysis of theories and research on these topics, that increased levels of empathy (and the cognitive and emotive components therein) are related to more mature identity development.

The theoretical frameworks can easily be overlapped to see that the developmental and psychosocial processes taking place are similar and interwoven. Cognitive developments experienced by adolescents enable them to see themselves from an objective standpoint and the ability to see the viewpoints of others both for the purpose of self-evaluation and empathic understanding. Previous research and theoretical 
analysis indicate that the coincidence of the timing of these developments in adolescents is not accidental. Resolution of Erikson's adolescent crisis of identity vs. identity confusion requires self-reflection and self-analysis. The ego strengths of fidelity, love, and care, all sharing an underlying theme of concern for others, seem to be related to empathy and perspective taking ability. These psychological traits of identity development (awareness of self) and empathy (awareness of others) seem to be based on overlapping cognitive abilities to understand the world from more than one point of view and assess what is found.

\section{Ego Identity, Empathy, and the Creative Process}

Does greater empathic concern encourage participation in creatively centered extracurricular activities and more advanced ego identity development? Each of these aspects of human development seem to enjoy a period of growth during adolescence. It is a popularly held belief that creative processes help to 'work out' emotional stress or confusion. Painters, poets, musicians, novelists, and dramatists have always been said to use the medium of their creative expression to sort out their own personal issues on the canvas, so to speak. The belief that artistic expression can be therapeutic has even reached into the academic and psychological realm, where art therapy and music are used to treat children, patients with dementia, in grief counseling, work with prison populations, and in other realms of psychological treatment. If creative expression can be so therapeutic, then might it not perhaps have some connection to the development of identity among adolescents? Utilizing these resources may help adolescents to sort out their thoughts and feelings, becoming more aware of self in the process. 
Waterman and Archer (1979) found that students who wrote poetry were more likely to have achieved identity formation than were students who did not write poetry or even those who wrote regularly, but only kept a journal of daily events and personal relations (also see Waterman, Kohutis \& Pulone, 1977). The idea is that creative expression of personal feelings is either more indicative of, or is perhaps a contributing factor to, more advanced identity exploration among adolescents. By extension, one might assume that other creative outlets, such as art, music, or drama may also be activities that could show some association with further exploration of one's identity.

Markstom, Li, Blackshire, and Wilfong (2004) examined participation in adultsponsored youth activities with regards to ego identity and its component ego strengths. They found that certain types of activities were associated with positive development of particular ego strengths. For instance, involvement in sports, volunteering, and school government and issues groups were associated with hope, will, purpose, competence, and wisdom. Some activities however were found to be associated with only one or none of the ego strengths (creative arts were associated only with care; religious involvement had no associated ego strength). In their longitudinal analysis of measures administered at two separate times, the authors suggested that those students who possessed greater ego strength may be the ones who seek out such activities to begin with. However, their findings suggest that involvement in such activities may not, in and of itself, enhance ego strengths, but is most likely compounded with several other factors, such as socioeconomic status. Nonetheless, involvement in extracurricular and creative activities was found to be an indicator of greater ego strength (and therefore identity). The connection this study hopes to find is that creative outlets may increase thinking about emotions 
which may increase empathy, which leads to greater understanding of others which leads to a greater understanding of self.

\section{Gender Differences}

Marked differences have been noted in research on adolescent behavior and development in the means of expression and general social behavior of male and female adolescents. Psychology as a science now generally regards that such differences are due to influences of both nature and nurture, though which traits are more influenced by each is still up for debate. Due to social programming and/or inborn genetic tendencies, girls and boys frequently choose different means of social interaction and personal expression and seem to exhibit different tendencies in the rate and volume of development for certain traits. For instance, girls tend toward earlier and more expressive verbal and emotional development and are more likely to comply with both peers and adults (Berk, 1994). Boys exhibit greater spatial capabilities as well as a tendency to take more risks and exhibit more language and behavior disorders (Berk, 1994). In social interaction, these differences manifest in the types of games played, toys used, and degree of aggressive or passive behavior expected of girls versus boys very early in life, as early as two years (Berk, 1994). Maccoby (1988) suggests that it is these existent differences in biological predisposition and cognitive categorizing, combined with socialization pressures that lead young children to form play groups in a very sex-segregated manner.

Gender differences have been especially noted in social contexts. Maccoby (1988) noted differences in styles of play and speech among each gender. Girls are generally more verbally expressive, forging intimacies with friends by sharing secrets and personal thoughts. They often express agreement with one another, take turns speaking, 
or acknowledge a previous statement from another girl—using speech as a tool for social binding. Boys, on the other hand, form friendships through shared experiences and group physical activities or adventures. Boys' interaction often shows use of dominance, boasting, threats, heckling, and joking — using speech in a more ego driven manner (Maccoby, 1988). Gender differences are evident in other areas of adolescent behavior. For instance, involvement in many extracurricular or volunteer activities is rather clearly delineated along gender lines: boys are more likely to be involved in team sporting activities, while girls are more likely to participate in more emotional and care oriented activities such as music and drama, or academic activities (Eccles \& Barber, 1999; Markstrom, et al., 2004). Many of these differences may be due in large part to social expectations, even sanctions against inter-gender participation in activities where strong gender associations already exist (i.e., sports or sewing).

Gender differences have been noted also, among measures of psychological development. Markstrom et al. (2004) found that girls score significantly higher on measures of certain ego strengths that are among those qualities most often associated with the female aspects of humanity: fidelity, love, and care, but also purpose. Allison and Schultz's (2001) study on interpersonal identity development found that among early adolescents (between ten and fourteen years) more girls than boys were found to be in the identity stages of foreclosure and diffusion. However, there was no gender difference found in the more advanced stages of moratorium and achievement. Lewis (2003) examined identity status among college students with respect to age, ethnicity and gender and found that in scores of overall identity development, there was no difference between men and women. When examining the interpersonal component of the measure, though, 
males were more likely to exhibit an identity status of diffusion or foreclosure than were females. Lewis (2003) noted also an interaction between age and gender-women scored higher on identity achievement at every age grouping but one (twenty-four to twenty-six years), where men scored highest. Gender may play an important role in development of and successful achievement of identity and the component ego strengths that assist in further ego development.

Empathy is another area in which developmental differences can vary by gender. Eisenberg, Zhou, and Koller's 2001 study on adolescent prosocial moral judgment and behavior examined gender and gender-role orientation as related to sympathy and perspective taking (a major component part of empathy). Their findings indicated that girls were more adept in areas of sympathy and prosocial behavior, but scores were not significantly different on measures of perspective taking. Eisenberg, et al. (2001) also found that among all participants, a feminine gender-role orientation predicted higher perspective taking ability and sympathy, both of which were predictors for moral reasoning. Eisenberg et al. (1991) noted higher scores for adolescent females on measures of empathy and helping behaviors at two different times in a longitudinal study. Davis (1983) found higher scores on all four subscales of his measure of empathy, noting that such gender differences were expected in the area of empathy research. Certainly these results indicate that gender and gender roles dictate how empathy and its component abilities are developed.

Franzoi, Davis, and Young's (1985) study examining how self-consciousness and perspective taking effect satisfaction in relationships discussed their findings regarding gender differences in empathy and perspective taking in terms of social roles. Empathy 
is a trait that is culturally ascribed to women as part of the expressive roles they are expected to play in relationship and family settings (Parsons \& Bales, 1955). Because men are expected to fulfill more instrumental roles in society, they are taught to focus more on task-oriented success and not as much on emotional needs. Franzoi et al. (1985) found these social tendencies were evident in their results when female participants' perspective-taking ability effected male satisfaction in the relationship, but the reverse was not true. They speculated that this finding was due to the fact that for women, perspective taking is very relevant to their expected social roles. Dyk and Adams (1990) investigated different theoretical models concerning gender and sex role differences in identity and found that advanced identity predicted more advanced intimacy. Feminine sex role orientation among some participants was associated with a stronger identity/intimacy link with femininity serving as a mediator (Dyk \& Adams, 1990).

Because previous findings have indicated that social involvement, development of identity, and development of perspective-taking and sympathy vary by gender, it is expected that there will be a noticeable difference between males and females on all measures. More females should be involved in adult-sponsored activities that are creatively and emotionally focused. More females are also expected to exhibit high scores on the measure of empathy and the ego strength of fidelity, as well as more mature identity status overall.

\section{Literature Review Summary}

Examining the existing theory and research on identity development and empathy, it seems logical that the two should be related; they are dependant on closely linked skills and knowledge. In fact, Erikson's discussion of his theory of psychosocial development 
was not at all limited to strictly cognitive changes, but incorporated emotional, maturational, and social developments - factors indicative of the psyche and awareness. Although empathy would seem to be a mostly emotive component of the human experience, a certain amount of cognitive and maturational growth is absolutely necessary to understanding the concepts involved in grasping someone else's emotional state. The same knowledge and skills which are necessary to understanding self and others (reason, perspective, care, etc.) are skills that are both requisite to and nurtured by the creative process. Participation in extracurricular activities has many positive outcomes for adolescents, including stronger identity and ego strength development (Markstrom, et al., 2004), and the small amounts of research done to examine creativity and identity did find at least that creative activities of a more reflective nature (creative writing) were associated with greater identity achievement (Waterman \& Archer, 1979). Imaginative play is stressed as very important to cognitive and ego development among children at the play and school ages (Bodrova \& Long, 2003). Cognitively it helps them work out logical story lines and imagine themselves as adults, and it is very important to social development as well. Adolescence is the time when creative activities and imagination become less concrete, more interpretive, and more introspective. If imagination is so important to helping children learn about the world and themselves, should creativity and imagination not also perform similar functions for adolescents, even adults? 


\section{CHAPTER THREE}

Methods

\section{Description of Participants}

Participants were 212 male and 320 female high school students between 14 and 18 years of age. Participants were in attendance at one of sixteen rural and suburban high schools in West Virginia. Most participants' ethnic/racial background was Caucasian/White. Socioeconomic status was determined using a mean score for mother's and father's occupation based on the Nakao and Treas (1992) rating scale. If only one parent was employed, that parent's score was used; data for students whose parents were unemployed, disabled, or otherwise unable to be classified were omitted from analyses involving SES. Letters describing the study with accompanying consent forms were sent to parents prior to data collection. Students also read and signed assent forms at the actual testing (see Appendix A).

The data used in this study was collected as part of a larger study carried out to examine several aspects of adolescent development and scholastic and community involvement. Participants completed a booklet-style set of questionnaires at two different times spaced eight months apart; data collection occurred in the spring of one academic year and in the fall of the following academic year. Extensive information about the individual's background was obtained via questions about gender, ethnicity, age, parents' occupational status, sibling order, and living arrangements. The data collection was also meant to evaluate the effectiveness of a new 4-H program implemented in the state. Only 25 of the surveyed students participated in the 4-H program, and their data was not included in this analysis. 


\section{Measures}

Two questions concerning creative activity asked if each student participated in a school-sponsored music group (choir, band, etc.) or drama class or club (see Appendix E). Four possible answers were available to these questions; (1) school/community does not offer, (2) did not participate, (3) participated, and (4) participated as officer/leader. For the purpose of this study, answers were collapsed into the dichotomous categories of participation and non-participation.

Ego identity status was assessed by means of the EOMEIS (Extended Objective Measure of Ego Identity Status) (Bennion, Adams, \& Huh, 1989) which consists of sixtyfour Likert-type questions assessing the individual's overall level of identity development. The EOMEIS assesses the individual's identity according to Marcia's four statuses (diffusion, moratorium, foreclosure, achievement), but the measure also can be analyzed according to eight subscales that assess different aspects of identity development. The four subscales used in this study measure areas of identity development related to ideology (politics, religion, occupation, and philosophy) (see Appendix B). The thirty-two items used were scored according to the four identity statuses and to obtain an overall identity development score. Items with negative wording were reverse coded for analysis. The other four subscales assess interpersonal domains including friendship, family, sex roles, and recreation, but were not used in this study.

Participants' level of empathy was assessed using the Interpersonal Reactivity Index (Davis, 1983) which is a twenty-eight item Lykert-type question measure, consisting of four seven-item subscales (see Appendix C). The four subscales measure 
perspective taking, empathic concern, fantasy, and personal distress; each subscale assesses a different portion of one's empathic ability. For this study the perspective taking, empathic concern, and personal distress subscales were used, for a total of twentyone questions. The fantasy subscale was excluded. Questions in each subscale relate the topic to everyday experiences such as relating to friends by trying to understand their perspective (perspective taking), or being scared in emotionally tense situations (personal distress). Davis noted in his 1983 article that gender differences were present in testing with females scoring higher on all four subscales. Davis also noted that this is par for the course when studying empathy — females seem to always score higher on all measures of empathy.

The PIES (Psychosocial Inventory of Ego Strengths) was developed by Markstrom et al. (1997) to assess the ego strengths that are integral to each stage of Erikson's ego identity development. There are eight ego strengths (hope, will, purpose, competence, fidelity, love, care, wisdom), one ascending to prominence with each stage of identity development; Erikson's epigenetic principle applies to ego strengths as well. All ego strengths are present in all stages of life, but each ego strength rises to ascendancy with its stage and identity crisis. The PIES measure consists of 64 questions using a Likert-type 5-point scale on a self-report questionnaire. The measure can be scored based on all 64 questions for a total ego strength score, or separated into eight subscales to obtain scores for each ego strength. Because the ego strength of fidelity is associated with adolescence and is expected to be related to creative thinking, it is the only ego strength assessed in this study. The fidelity subscale consists of eight questions (see Appendix D). 


\section{Statistics}

Analyses for the data collected in this study were separated for each hypothesis. Because of the number of different independent variables in each hypothesis, the differences between means were assessed using analysis of variance rather than more simple t-tests. Gender was considered to be a factor in each of the other hypotheses, therefore it was integrated into the analysis for those hypotheses and was not given its own separate examination.

The first hypothesis predicated that adolescents who exhibited greater empathy would be more likely to be involved in creative activities and that female gender would be associated with higher levels of both. In order to test this, a $2 \times 2$ (participation $\mathrm{x}$ gender) ANOVA was used to determine if there was interaction between gender, participation, and empathy. The second hypothesis stated that adolescents with greater empathy would show greater identity development. Again, gender was expected to impact both empathy and identity development. Because there were two measures of identity (ego identity status and the ego strength of fidelity) two separate analyses were run. The first was a partial correlation for empathy and fidelity (controlling for gender), the second a $4 \times 2$ (identity $\mathrm{x}$ gender) ANOVA for the four identity statuses by empathy, factoring in gender.

The third hypothesis postulated that involvement in creative extracurricular activities would be associated with greater identity development, including gender as a factor. To test both the fidelity ego strength and the four ego identity statuses required separate analyses. A 2x2 (participation $\mathrm{x}$ gender) ANOVA was run for fidelity and participation, including gender as a variable. To compare the four ego identity statuses 
against participation and gender, Crosstabs and Chi Square tests were performed to assess the percentages of participants or non-participants of each gender by identity statuses. The fourth hypothesis stated that identity development would be most advanced among those who exhibited greater empathy and participated in creative activities; including the possible effect of gender on each of the above. Multiple regression analysis using empathy, participation, and gender as predictors was used to find the line of best fit with a criterion variable of identity. 


\section{CHAPTER FOUR}

Results

Reliability analysis was performed using Chronbach's alpha for each of the measures used in this study. Reasonably good reliability was found for the items in each of the EOMEIS identity status subscales: diffusion $(\alpha=.62)$, moratorium $(\alpha=.64)$, foreclosure $(\alpha=.74)$, achievement $(\alpha=.66)$. Chronbach's alpha for the items in each of the subscales of the Interpersonal Reactivity Index used to evaluate empathy were as follows: perspective taking $(\alpha=.69)$, empathic concern $(\alpha=.82)$, personal distress $(\alpha=$ .72). Reliability analysis was also good for the items in the fidelity subscale of the PIES measure which was used in this study $(\alpha=.62)$.

Statistical analyses of the data showed some support for the hypotheses, drawing special attention to the role of gender in the relationship between identity development and both creative activity participation and empathy. While the relationship between creative activity participation and identity was not statistically significant, there was some marginal significance when gender was included. The relationship model was altered to reflect the correlations actually discovered for the research variables (see Figure 3). There were significant relationships for empathy and creative activity involvement and for identity/ fidelity and empathy. Gender was significantly related to each of the variables and may serve as a mediating factor for a slight significance between creative activity participation and identity. 


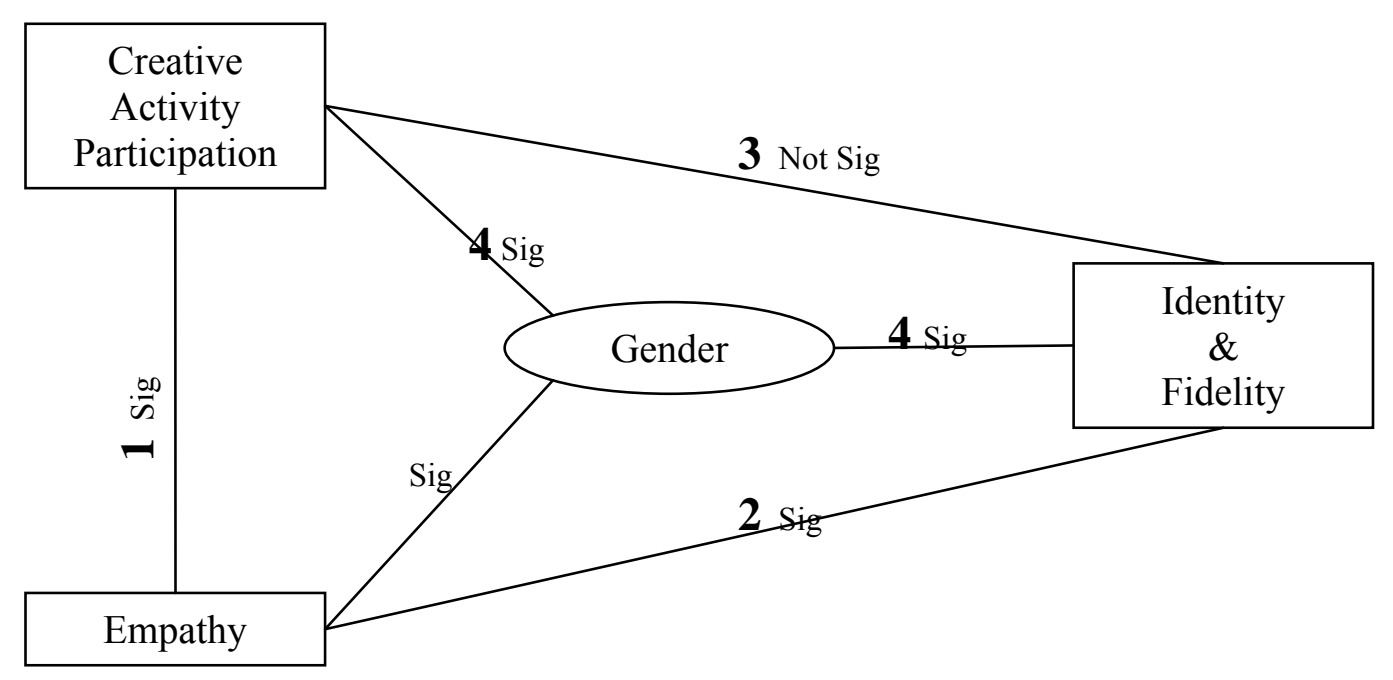

Figure 3. The relationships between creative activity participation, empathy, and identity, with gender as a significantly influential factor. Numbers indicate which hypothesis describes each relationship.

\section{Hypothesis1}

The first hypothesis assumed that a higher score on the measure of empathy would be significantly related to participation in creative activities, especially for girls, who were expected to exhibit higher levels of both variables. MANOVA, which is a comparison of means rather than a correlation, was used to examine the relationships between empathy, creative activity participation, and gender. A $2 x 2$ (gender $\mathrm{x}$ participation) MANOVA controlled for multicollinearity among the three related subscales of the empathy measure. Results of the Wilks' Lambda tests were first examined to determine if multivariate analyses were significant. There was a significant relationship, $F(3,513)=22.04, p<.00$, for gender and empathy. A relationship was also found between creative activity involvement and empathy, $F(3,513)=2.34, p<.07$, but was not quite significant. Lambda for the empathy subscales by both gender and creative activity involvement did not yield significant results. Where the multivatiate tests were 
significant, univariate tests were performed to isolate further connections amongst the variables.

Univariate tests of between-subjects effects also found significant relationships for gender and empathy on all three of the empathy subscales: empathic concern, $F(1,3$, $515)=39.63, p<.000$, perspective taking, $\mathrm{F}(1,3,515)=25.20, \mathrm{p}<.000$, and personal distress, $F(1,3,515)=8.03, p<.005$. Mean scores for each of the empathy subscales were higher for females than for males. The univariate tests did yield a significant finding for creative activity involvement as related to empathic concern, $F(1)=6.53$, $p<.01$, where mean scores of students who participated were higher than those for students who did not participate. There were no significant relationships found for the other two empathy subscales when examined by creative activity participation. Means for all three empathy subscales by gender were within $95 \%$ confidence intervals, as were the means for empathic concern subscale by creative activity participation (Table 2).

Table 2

Means of Empathy Subscales by Gender and Creative Activity Participation

\begin{tabular}{l|lll}
\hline Empathy Subscale & Gender & Mean & SE \\
\hline Empathic Concern & Male & 25.10 & .45 \\
& Female & 28.47 & .30 \\
Perspective Taking & Male & 22.83 & .26 \\
& Female & 25.22 & .26 \\
Personal Distress & Male & 17.36 & .42 \\
& Female & 18.79 & .28 \\
\hline Empathy Subscale & Creative & Mean & SE \\
\hline Empathic Concern & Did not Participate & 26.10 & .29 \\
& Participated & 27.47 & .45 \\
\hline
\end{tabular}

Hypothesis 2

Hypothesis two stated that those adolescents with a higher score on a measure of empathy would also show more advanced identity development. A partial correlation 
controlling for gender was run for the ego strength of fidelity and for the four identity status subscales, finding mostly significant results. Table 3 shows the coefficients of correlations $(r)$ and significance values.

Table 3

Correlations Between Empathy Subscales and Identity Statuses and Fidelity

\begin{tabular}{c|cccccc}
\hline $\begin{array}{l}\text { Empathy } \\
\text { Subscale }\end{array}$ & & Diffusion & Foreclosure & Moratorium & Achievement & Fidelity \\
\hline Empathic & $r$ &. .247 & -.128 & -.072 & .276 & .347 \\
Concern & $p$ & .000 & .004 & .104 & .000 & .000 \\
\hline Perspective & $r$ &. .199 & -.107 & -.047 & .194 & .232 \\
Taking & $p$ & .000 & .015 & .286 & .000 & .000 \\
\hline Personal & $r$ & .217 & .257 & .186 & -.176 & -.357 \\
Distress & $p$ & .000 & .000 & .000 & .000 & .000 \\
\hline
\end{tabular}

Note: Significant findings are in bold.

Most of the correlations were significant, the exceptions being the relations between moratorium and empathic concern and perspective taking. As noted above, empathic concern and perspective taking are considered the more positive (good) aspects of empathy, while personal distress is considered a negative or destructive (bad) way of using empathic ability. Correlations to the various statuses of identity development, then should reflect positive correlations between good types of empathy and more advanced identity statuses, for instance, perspective taking and identity achievement, and negative correlations between the bad type of empathy and the more advanced stage of identity development. As shown in Table 3, diffusion, foreclosure, and moratorium are negatively correlated with empathic concern and perspective taking while being positively correlated to personal distress. Identity achievement and the ego strength of fidelity are both positively correlated to empathic concern and perspective taking, but negatively correlated with personal distress. 


\section{Hypothesis 3}

The third hypothesis stated that if participation in creatively centered activities does encourage thinking about emotion and empathy, it should be related to increased awareness of self. Therefore, creative activity participation should be positively correlated with more advanced identity development. Identity development was again measured by two different scales, the four statuses of identity development and fidelity. A $2 \times 2$ (gender $x$ participation) MANOVA was run for the subscales of identity diffusion, moratorium, foreclosure, and achievement. Wilks' Lambda was significant for gender, $F$ $(4,523)=3.21, p<.013$, and marginally significant for the interaction between gender and creative activity participation, $F(4,523)=1.9, p<.093$. Analyses for the four statuses of identity development showed little connection in the expected relationship between creative activities and identity development. There was a significant relationship for gender and diffusion, $F(1,526)=3.71, p<.05$, and for gender and foreclosure, $F(1,526)$ $=9.28, p<.002$. Males scored higher than females on both the diffusion and foreclosure subscales, which represent less movement toward resolving the identity crisis (see Table 4). No significant effects were found between creative activity participation and identity status.

Table 4

Means of Identity Status Subscales by Gender

\begin{tabular}{l|lcc}
\hline Identity Subscale & Gender & Mean & SE \\
\hline Identity Diffusion & Male & 27.01 & .51 \\
& Female & 25.84 & .34 \\
Identity Foreclosure & Male & 24.27 & .56 \\
& Female & 22.22 & .34 \\
\hline
\end{tabular}


The hypothesized link between creative activity involvement and identity development was not directly supported. A significant relationship was only found between gender and identity, while the relationship between gender/creativity/identity fell short of the significant standard. The multivariate test for gender and creative activity involvement was only marginally significant, but because there was a relationship between gender and identity and a relationship where gender and creativity intersect identity, it seemed worthwhile to examine univariate tests.

While there was also no significant direct interaction between creativity and identity among the univariate tests, a significant interaction, $F(1,526)=7.48, p<.006$, was found for the identity status of moratorium when gender was added to the analysis. The effect of gender on scores of identity development by creative activity participation can be seen in the mean scores for moratorium (see Figure 4). Participation did not significantly vary moratorium scores for females, but mean scores for males in moratorium were higher among those who did not participate, indicating perhaps the creative involvement may be more of a boost to the soul-searching that is the moratorium stage for males than for females. A marginally significant relationship, $F(1,526)=2.95$, $p<.087$, was also found for identity diffusion and creative involvement when gender was added (see Figure 5). Among those who participated, diffusion scores were about the same for males and females. Among those who did not participate, diffusion scores were slightly lower for females; males who did not participate scored notably higher on the diffusion subscale, meaning they have not begun to analyze their identity crisis. 


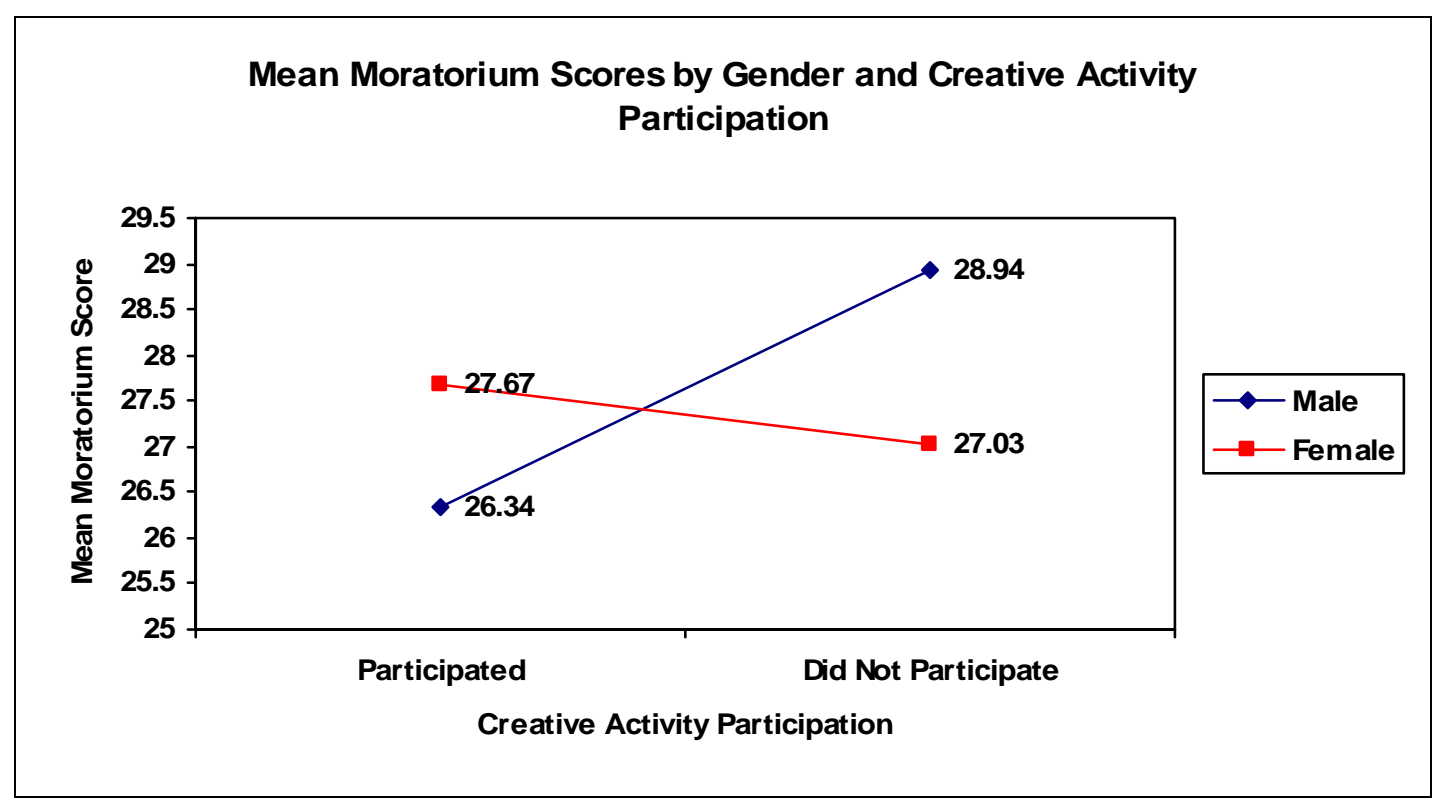

Figure 4. Mean scores for the identity status of moratorium by gender and creative activity participation.

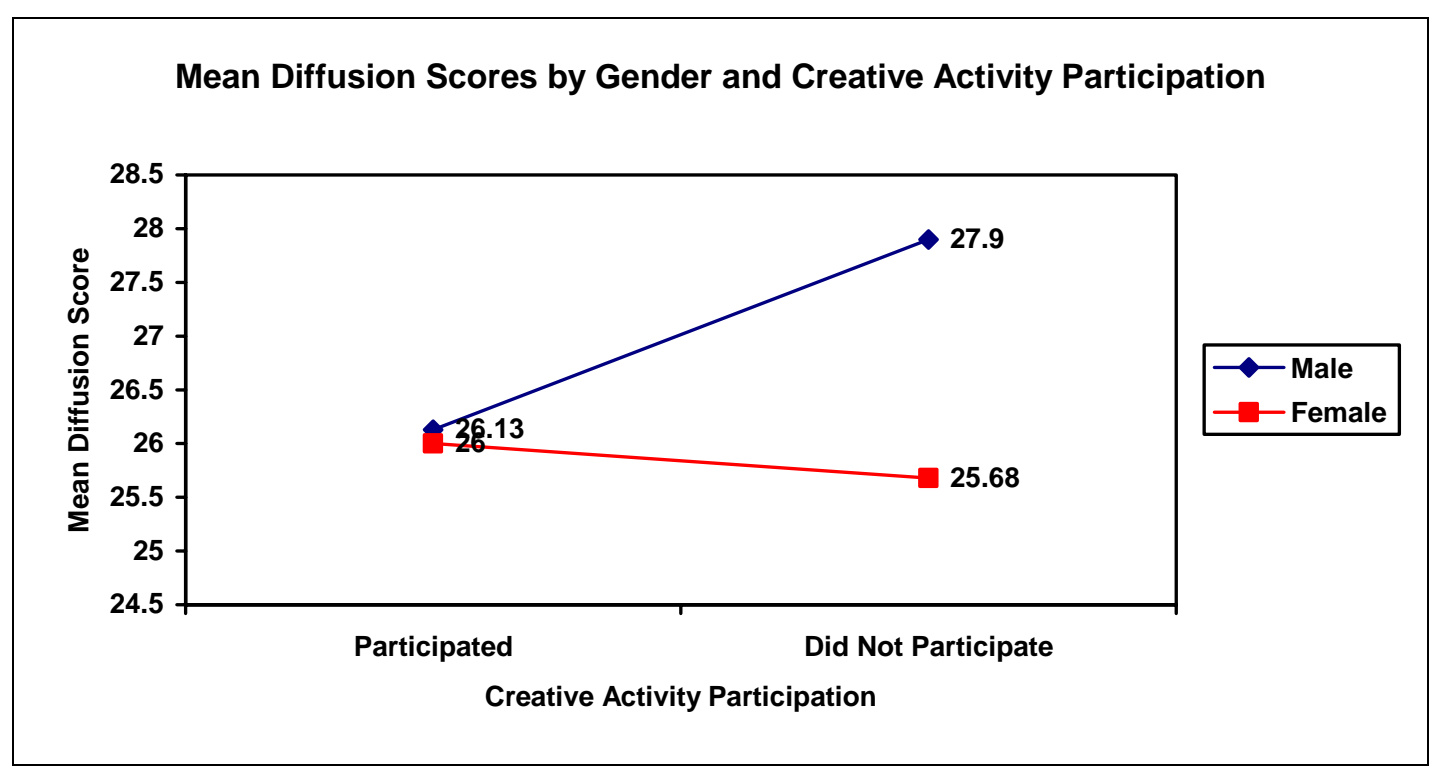

Figure 5. Mean scores for the identity status of diffusion by gender and creative activity participation.

The second measure of identity development was the adolescent ego strength of fidelity, assessed by a $2 \times 2$ (gender x participation) ANOVA. Here, again, there was little support for a direct interaction between fidelity and creative activity participation ( $\mathrm{F}$ tests 
were not significant), but gender seemed to play a part in connecting the two. A significant interaction was seen for gender and fidelity, $F(1,526)=20.56, p<.00$, and there was a nearly significant relationship when gender and creative activity participation were compared for fidelity, $F(1,526)=3.43, p<.07$. Mean scores for fidelity by gender were 29.37 for males and 31.39 for females. Mean scores for gender by creative participation for fidelity also showed a gender difference (Figure 6). Females scored notably higher than males on the measure of fidelity among those who participated in creative activities and those who did not. Males who participated in creative activities did score higher than males who did not, again suggesting that participation in creative activities may be more beneficial for boys in helping to develop their ego identity. Although a direct relationship between identity development and creative activity participation was not identified, there appears to be a possible mediating effect when gender is introduced into the analyses. In examining both measures of identity, it was found that gender was significantly related to identity development (as was expected from the review of literature.) Both analyses also found that although creative activity participation could not be directly related to identity status or fidelity, when gender was calculated into the mix, a relationship became clearer. 
Mean Fidelity Scores by Gender and Creative Activity Participation

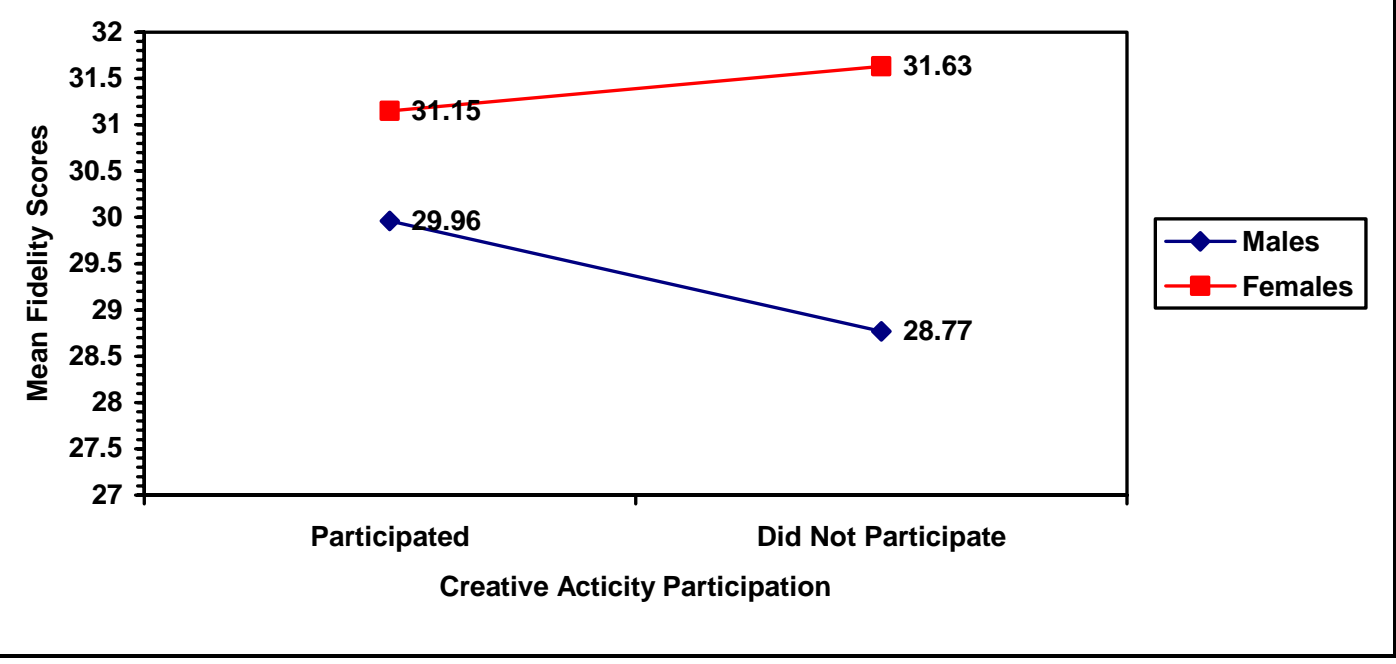

Figure 6. Mean fidelity scores by gender and creative activity participation.

\section{Hypothesis 4}

The fourth and most complex hypothesis stated that identity development would be most advanced among adolescents who exhibited higher levels of empathy and participated in creative activities. Because of the number of variables involved, analysis was done by stepwise regression. The ego strength of fidelity and the identity status of achievement were used as measures of identity and analyzed separately. The three other identity statuses in Marcia's model were not included because it was determined that identity achievement would be the best indicator of strong identity.

Where several variables are closely related, a stepwise regression can tease out which variables most impact the dependent variable step by step, and which combination of variables best predicts the outcome. Further, it accounts for the amount of variability each variable contributes to the equation. Regressions were performed for fidelity and identity achievement where gender, creative activity involvement, and the three subscales 
of the empathy measure were predictors for the variability in each. Significant positive relationships were found for fidelity with empathic concern and gender; personal distress showed a significant negative relationship. The criterion for inclusion in the regression was probability of $F$ value between .05 and .10 , therefore only three variables were included: the empathy subscales of empathic concern and personal distress and gender. The regression model first assessed variability in fidelity attributable to empathic concern $\left(\mathrm{R}^{2}=.16\right)$, step two added personal distress $\left(\mathrm{R}^{2}=.22\right)$; at step three of the regression gender was added to the model, accounting for the remaining measure of variability in fidelity $\left(\mathrm{R}^{2}=.25\right)$. Table 5 displays findings for stepwise regression of fidelity. All variables included in the regression model account for a shared variance of $3 \%$. Note that while empathic concern exhibits a positive relationship with fidelity, personal distress exhibits a negative relationship.

Table 5

Summary of Regressions for Variables Predicting Fidelity

\begin{tabular}{|c|c|c|c|c|c|}
\hline Variable & $B$ & SE B & B & $s r^{2}$ & $t$ value \\
\hline Step 1: Empathic Concern ${ }^{2}$ & .24 & .03 & .29 & .09 & $6.94^{*}$ \\
\hline Step 2: Personal Distress ${ }^{b}$ & -.26 & .04 & -.29 & .09 & $-7.24^{*}$ \\
\hline Step 3: Gender ${ }^{\mathrm{C}}$ & 1.74 & .39 & .18 & .04 & $4.46^{*}$ \\
\hline
\end{tabular}

${ }^{\mathrm{a}} \mathrm{R}^{2}=.16, p<.000 .{ }^{\mathrm{b}} \Delta \mathrm{R}^{2}=.06, p<.000 .{ }^{\mathrm{c}} \Delta \mathrm{R}^{2}=.03, p<.000$ ${ }^{*} p<.000$

Stepwise regression for identity achievement found significant relationships with only empathic concern and with personal distress. Again the criterion was a probability of $F$ value between .05 and .10 , meaning only empathic concern and personal distress were included in the regression model. Step one assessed variability for empathic concern $\left(\mathrm{R}^{2}\right.$ $=.09$ ), entered into the equation at step 1 , and step two added personal distress (total $\mathrm{R}^{2}=$ .10). It is worth noting that higher empathy (empathic concern) does seem to share a 
positive relationship with identity achievement and fidelity, while lower empathy (personal distress) seems negatively related to both measures of identity. Table 6 displays the findings for stepwise regression of identity achievement. Both variables included in the regression model account for a shared variance of $1 \%$.

Table 6

Summary of Regressions for Variables Predicting Identity Achievement

\begin{tabular}{|c|c|c|c|c|c|}
\hline Variable & $B$ & SE B & $\beta$ & $s r^{2}$ & $t$ value \\
\hline Step 1: Empathic Concern ${ }^{a}$ & .27 & .04 & .27 & .08 & $6.31^{*}$ \\
\hline Step 2: Personal Distress ${ }^{b}$ & -.13 & .05 & -.11 & .01 & $-2.61^{* *}$ \\
\hline
\end{tabular}

${ }^{\mathrm{a}} \mathrm{R}^{2}=.09, \mathrm{p}<.000 .{ }^{\mathrm{b}} \Delta \mathrm{R}^{2}=.01, \mathrm{p}<.0009$.

${ }^{*} p<.000 .{ }^{* *} p<.009$ 


\section{CHAPTER FIVE}

\section{Discussion}

This study was carried out in order to determine if connections exist between involvement in creative activities, empathy, and identity development in adolescents. The data did show a fairly strong correlation between empathy and identity development, but failed to provide a direct link between creative activity participation and identity. However, there was some evidence that participation in creatively centered activities may be related to identity when gender acts as a mediator.

The first hypothesis examining empathy and creative activity participation was, in part, supported by the analysis. Although creative activity participation was not significantly related to the perspective taking or personal distress components of empathy, creative activity involvement was significantly related to empathic concern. This would tend to support the notion that the emotive part of empathy is linked to creativity in adolescents. Gender was found to be significantly related to empathy, with girls scoring higher on the measure of empathy, as was expected due to findings of previous research (Davis, 1986; Markstrom et al., 2004).

Support for the second hypothesis was found in the form of strong correlations between empathy/identity and empathy/fidelity. The direction of the correlations between the subscales of empathy and identity suggest that identity achievement is linked to the 'positive' portions of empathic thinking, i.e. empathic concern and perspective taking. The less advanced stages of identity development (diffusion and foreclosure) exhibited a significantly negative relationship with empathic concern and perspective taking and a positive relationship with personal distress. Such relationships demonstrate 
that empathy and identity are at least overlapping psychological constructs - that if an adolescent is experiencing high levels of personal distress, they most likely have not yet achieved identity. Those adolescents who are identity achieved have already mastered the skills necessary for empathic concern and perspective taking.

Fidelity was also positively correlated with empathic concern and perspective taking, while exhibiting a negative correlation with personal distress. This stands to reason, as fidelity is the ego strength that represents an individual's capacity for commitment, to self and others, and to ideals and beliefs. The ability to see others' perspectives and to feel concern for them would seem necessary to forming the kinds of commitments exhibited by an individual with high fidelity. Certainly it seems that the same types of cognitive and emotional growth that are required for empathy to develop should also be important in the formation of identity and the ego strengths gained in overcoming each psychosocial crisis.

The third hypothesis assumed creative activity participation would be related to more advanced identity development. There were no significant effects for the direct interaction of creative activity participation and identity development, but gender may serve as a possible mediating variable. For the moratorium subscale of identity status, scores were higher for girls who participated than those who did not; the opposite was true for boys and with a greater difference in scores of participants vs. non-participants. Boys who did not participate had the highest moratorium scores overall. Findings for the diffusion subscale of identity status also showed marked differences by gender, with nonparticipating males scoring much higher on diffusion (the pre-exploratory identity status) 
than females. Males who did participate in creative activities, however, scored nearly identically with the females who participated.

The fidelity measure also failed to find a direct relationship with creative activity participation, but gender seemed to greatly impact the interaction here too. Girls generally scored higher on fidelity anyway and showed no difference between participation and non-participation, but boys who participated did score better than those who did not. While analysis of identity status and fidelity did not yield a direct relationship with creative activity involvement, both showed a possible link to creative activity participation through the mediating variable of gender. In the context of this study, it would appear that participation in creative activities had a larger impact on males than on females, perhaps due to the already inflated scores on identity and fidelity found among girls. Perhaps a sort of ceiling effect is in place here for the girls, meaning that while creative outlets may help adolescents in sorting out identity and empathy, girls are already thinking about these things and do not get the same benefit received by the slower-developing boys.

Examination of the first regression performed to assess the fourth hypothesis found that fidelity was positively related to gender, with girls scoring higher. These findings are congruent with previous research, where Markstrom et al. (2004) and Markstrom and Kalmanir (2001) both concluded that the ego strength of fidelity was correlated to gender. Fidelity was also positively related to empathic concern and negatively correlated to personal distress. The significant correlations between fidelity and empathy make sense according to Davis' (1983) description of the role each 
component of empathy plays; fidelity should increase as empathic concern creates more awareness of others and fail to increase where personal distress is higher.

In the second regression, identity achievement was not found to be related to gender, nor to creative activity involvement, but was related to the empathy subscales of empathic concern (positively) and personal distress (negatively). The relationships support the theoretical constructs and the previous research on empathy, although it is notable that the perspective taking component of empathy was not found to be related to identity achievement, nor to fidelity. The regression analysis tries to discern which variables account for the largest portions of the variability in the dependent measure; in this case the perspective taking subscale did not account for a sufficient portion of that variability to be significant after gender and the other empathy subscales were tested. It is also notable that gender was not found to be associated with identity achievement, when previous research has shown a relationship there. It is likely that the variance attributable to gender was subsumed by the empathy subscale variables.

Creative activity participation was not found to be a significant factor in the regression analyses for either fidelity or identity achievement, again this is likely due to the greater contributions to variance among other variables. Although the regressions performed could not confirm the hypothesis that identity development would be more advanced in those adolescents who both had higher empathy and participated in creative activities, it did establish that both measures of identity were higher among adolescents with greater empathy and that gender plays a role in this relationship. 


\section{Limitations}

While the outcome of this study should prove useful in illustrating that some connection does exist between ego identity development and empathy, no strong evidence was found for direct association between identity and creative activity participation among adolescents. A marginal relationship was found between overall empathy and creative activity participation. One aspect of empathy, empathic concern, was significantly related to creative activity participation, but no other relationships with creative activity were found to be statistically significant. However, because gender seems to have the possibility to serve as a mediating variable, it may be true that identity achievement and fidelity as well as empathy and creative participation are each so strongly 3 influenced by gender that it effects the interrelation of the all of these relationships.

This study was somewhat limited in scope regarding the depth of information about creative endeavors because the measures were administered as part of a larger survey that focused on many areas of adolescent psychological development and not exclusively on creativity, empathy, and identity. The questions about creative activities were only a few items in a section of the survey about many extracurricular activities and asked only about music (band/choir, etc.) and drama. Previous studies on creativity and identity (Waterman \& Archer, 1979) have focused on other types of creative pursuits, such as creative writing and journaling. Waterman and Archer (1979) compared different types and levels of involvement in creative writing, from journaling to poetry and found significant differences where impact to identity was concerned. 


\section{Suggestions for Future Research}

A more specific and narrowly focused collection of data with more targeted questions would help in determining which aspects of creative involvement impact both identity and empathy. Examining different types of creative pursuits, like writing, visual arts, as well as more detailed information about performing arts should enable us to get a better picture of what it is about these activities that may or may not be valuable in developing a stronger sense of self and greater appreciation of other's feelings. In order to see how creative activities may increase introspection about identity and empathy, we need to ask questions about how studying music, drama, art, etc. makes them feel and think. Do students who feel passionately involved in music exhibit greater identity development than those who are just in the band? The Waterman and Archer study showed that poetry, which is considered to be more personal and introspective, did more for advancing identity development than just journaling, which amounted to recording one's daily activities.

The results of this study show some interesting associations between identity, empathy and perhaps creative activity participation through the filter of gender. The implication of these associations is that we should further examine how they (empathy and identity and creativity) may be linked so that the information gleaned from research can be used to help adolescents grow into confident, healthy adults and to let adults better understand what they can do to encourage positive development in all areas. 


\section{REFERENCES}

Adams, G.R. (1976). Personal identity formation: A synthesis of cognitive and ego psychology. Adolescence, 12(46), 151-164.

Adams, G.R., Benion, L., \& Huh, K. (1989). Objective Measure of Ego Identity Status: A reference manual. Available from Gerald Adams, Department of Family Studies, University of Guelph, Guelph, Ontario, Canada.

Ainsworth, M.D.S. \& Bell, S.M. (1970). Attachment, exploration, and separation: Illustrated by the behavior of one-year-olds in a strange situation. Child Development, 41, 49-67.

Ainsworth, M.D. (1962). The effects of maternal deprivation: A review of findings and controversy in the context of research strategy. In Deprivation of Maternal Care: A Reassessment of its Effects. Public Health Papers No. 14. Geneva: WHO.

Ainsworth, M.D. (1967). Infancy in Uganda: Infant Care and the Growth of Attachment. Baltimore, M.D.; The Johns Hopkins Press.

Allison, B.N. \& Schultz, J.B. (2001). Interpersonal identity formation during early adolescence. Adolescence, 36, 509-23.

Barber, B.L., Eccles, J.S. \& Stone, M.R. (2001). Whatever happened to the jock, the brain, and the princess? Young adult pathways linked to adolescent activity and social identity. Journal of Adolescent Research, 16(5), 429-455.

Bennion \& Adams, G.R. (1986). A revision of the extended version of the objective measure of ego identity status: An identity instrument for use with late adolescents. Journal of Adolescent Research,1 183-198.

Berk, L.E. (1994). Child Development, $3^{\text {rd }}$ Ed. Boston: Allyn and Bacon. 
Bodrova, E. \& Leong, D.J. (2003). The importance of being playful. Educational Leadership, April, 50-53.

Carlson, N.R. \& Buskist, W. (1997). Psychology: The science of behavior (5 ${ }^{\text {th }}$ ed.). Boston: Allyn and Bacon.

Damon, W. (1983). Social and personality development. New York: W.W. Norton \& Company.

Davis, M.H. (1983). Measuring individual differences in empathy: Evidence for a multidimensional approach. Journal of Personality and Social Psychology, 1, $113-126$.

Dusek, J.B. (1996). Adolescent development and behavior ( $3^{r d}$ Ed.). Upper Saddle River, New Jersey: Prentice-Hall, Inc.

Dworkin, J.B., Larson, R. \& Hansen, D. (2003). Adolescents' accounts of growth experiences in youth activities. Journal of Youth \& Adolescence, 32(1), 17-26.

Dyk, P.H. \& Adams, G.R. (1990). Identity and intimacy: An initial investigation of three theoretical models using cross-lag panel correlations. Journal of Youth and Adolescence, 19(2), 91-110.

Eccles, J.S., \& Barber, B.L. (1999). Student council, volunteering, basketball, or marching band: What kind of extracurricular involvement matters? Journal of Adolescent Research, 14, 10-43.

Eisenberg, N., Miller, P., Shell, R., McNalley, S. \& Shea, C. (1991). Prosocial development in adolescence: A longitudinal study. Developmental Psychology, 27(5), 849-857. 
Eisenberg, N., Zhou, Q. \& Koller, S. (2001). Brazilian adolescents' prosocial moral judgment and behavior: Relations to sympathy, perspective taking, gender-role orientation, and demographic characteristics. Child Development, 72(2), 518-534.

Enright, R.D. \& Deist, S.H. (1979). Social perspective taking as a component of identity formation. Adolescence, 14, 517-522.

Erikson, E.H. (1950). Childhood and society. (35 ${ }^{\text {th }}$ Anniversary Edition). New York: W.W. Norton \& Company.

Erikson, E.H. (1968). Identity: Youth and crisis. New York: W.W. Norton \& Company.

Erikson, E.H. (1997). The life cycle completed. (Extended version with new chapters on the ninth stage of development by J.M. Erikson). New York: W.W. Norton \& Company.

Fitch, S.A. \& Adams, G.R. (1983). Ego identity and intimacy status: Replication and extension. Developmental Psychology, 19(6), 839-845.

Franzoi, S.L., Davis, M.H., \& Young, R.D. (1985). The effects of private selfconsciousness and perspective-taking on satisfaction in close relationships. Journal of Personality and Social Psychology, 6, 1584-1594.

Glanville, J.L. (1999). Political socialization or selection? Adolescent extracurricular participation and political activity in early adulthood. Social Science Quarterly, $80,279-290$.

Guest, A. \& Schneider, B. (2003). Adolescents' extracurricular participation in context: The mediating effects of schools, communities, and identity. Sociology of Education, 76(2), 89-109. 
Hawkes, G. R. \& Egbert, R.L. (1954). Personal values and the empathic response: Their interrelationships. Journal of Educational Psychology, 45, 469-486.

Lange, C. \& Byrd, M. (2002). Differences between students' estimated and attained grades in a first year introductory psychology course as a function of identity development. Adolescence, 37, 93-107.

Lewis, H. (2003). Differences in ego identity among college students across age, ethnicity, and gender. Identity, 3(2), 159-189.

Lindsay, M.M. (1995). Self-in relation theory: Relational identity, accurate empathy, and self-esteem in adolescent females. Dissertation Abstracts International, 56 (6B), 3477.

Maccoby, E.E. (1988). Gender as a social category. Developmental Psychology, 24(6), $755-765$.

Marcia, J.E. (1966). Development and validation of ego-identity status. Journal of Personality and Social Psychology, 3, 551-558.

Marcia, J.E. (1996). The empirical study of ego identity. In H.A. Bosma, T.L.G. Graafsma, et al. (Eds.). Identity and development: An interdisciplinary approach. Thousand Oaks: Sage Publications. (pp. 67-81).

Marcia, J.E. (2002). Adolescence, identity, and the Bernardone family. Identity: An International Journal of Theory and Research, 2(3), 199-209.

Markstrom, C. A. \& Kalmanir, H.M. (2000). Linkages between the psychosocial stages of identity and intimacy and the ego strengths of fidelity and love. Identity: An International Journal of Theory and Research, 1, 179-196. 
Markstrom, C.A., Li, X., Blackshire, S., \& Wilfong, J. (2004). Adolescent involvement in structured activities and positive youth development. In 2001 Annual Report: West Virginia Agricultural and Forestry Experiment Station. Morgantown, WV: West Virginia University.

Markstrom, C.A., Sabino, V.M., Turner, B.J. \& Berman, R.C. (1997). The psychosocial inventory of ego strengths: Development and validation of a new Eriksonian measure. Journal of Youth and Adolsecence, 26(6), 75-731.

Markstrom-Adams, C., Ascione, F.R., Braegger, D. \& Adams, G.R. (1993) Promotion of ego-identity development: Can short-term intervention facilitate growth? Journal of Adolescecne, 16(2), 217-224.

Neuber, K.A. \& Genthner, R.W. (1977). The relationship between ego identity, personal responsibility, and facilitative communication. The Journal of Psychology, 95, 45-49.

Parsons, T. \& Bales, R.F. (1955). Family socialization and interaction process. New York: Free Press of Glencoe.

Piaget, J. \& Inhelder, B. (1969). The psychology of the child. New York: Basic Books, Inc.

Strietmatter, J.L. (1989). Identity development and academic achievement in early adolescence. Journal of Early Adolescence, 9(1-2), 99-111.

Waterman, A.S. \& Archer, S. (1979). Ego identity status and expressive writing among high school and college students. Journal of Youth and Adolescence, 8(3), 327341. 
Waterman, A.S. \& Waterman, C.K. (1972). Relationship between freshman ego identity status and subsequent academic behavior: A test of the predictive validity of Marcia’s categorization system for identity status. Developmental Psychology, 6(1), 179.

Waterman, A.S., Kohutis, E., \& Pulone, J. (1977). The role of expressive writing in ego identity formation. Developmental Psychology, 13(3), 286-287. 


\section{APPENDICES}


APPENDIX A

Consent Forms 


\section{PARENTAL OR GUARDIAN CONSENT FORM - CHARTING PARTICIPANTS}

\section{Effects of the 4-H Charting Program on the Development of Youth}

Introduction. I, , have been asked to allow my adolescent

to participate in this study, has explained the study to me.

Purposes of the Study. I have been told that eh purpose of this study is to learn more about the Charting Program offered through 4-H to teenagers, like my own, in West Virginia. The researchers are interested in identifying the positive effects of Charting on the development of youth.

Description of Procedures. The study will be performed in the Extension office. I understand that my teenager's involvement in Charting is separate from his/her participation in this research study. My teenager will be asked to complete a set of questionnaires at three different times over the next year and a half. The questions will be related to how he/she feels about him/herself, his/her relationships with others, how he/she makes decisions, and similar topics. My teenager does not have to answer all of the questions. It will take him/her one to two hours to answer the questions. There will be several hundred West Virginia adolescents from ages 14 through 19 in the study.

Discomforts. The questions are not supposed to be difficult of disturbing to my adolescent. The only inconvenience is the time that will be given to the study.

Benefits. I understand that this study will help 4-H and Extension services learn more about how Charting helps teenagers.

Contact Persons. For more information about this research, I can contact Dr. Carol Markstrom at (304) 293-3402 ext. 1775 or Dr. Patty Mulkeen at (304) 293-2796 ext. 3438 .

For information regarding my child's rights asa a research subject, I may contact the Executive Secretary of the Institutional Review Board at (304) 293-7073.

Confidentiality. I understand that any information obtained as a result of my adolescent's participation in this research will be kept as confidential as legally possible. I understand that these research records, just like hospital records, may be subpoenaed by court order or may be inspected by federal regulatory authorities. However, I also know that results from this research, neither my name nor that of my adolescent nor any information from which we might be identified will be published. 
Voluntary Participation. Participation in this study is voluntary. I understand that I may withdraw my adolescent from this study at any time. Refusal to participate of withdrawal will involve no penalty or loss of benefits for me or my adolescent. I have been given the opportunity to ask questions about the research, and I have received answers concerning areas I did not understand. Upon signing this form, I will receive a copy.

I willingly consent to my adolescent's participation in this study.

Signature of Parent or Guardian

Date

Time

Signature of Investigator or

Date

Time

Investigator's Representative 


\section{ASSENT FORM - NON-CHARTING PARTICIPANTS}

Effects of the 4-H Charting Program on the Development of Youth

Introduction. I, , have been asked to be in this research study, which has been explained to me by

Purposes of the Study. I have been told that the purpose of this study is to learn more about the Charting Program offered through 4-H. The researchers are interested in identifying the positive effects of Charting on the development of youth.

Description of Procedures. Even though I am not in Charting, I understand that the researchers need other teenagers to complete a set of questionnaires at three different times over the next year and a half. The questions will be related to how I feel about myself, my relationships with others, how I make decisions, and similar topics. I do not have to answer all of the questions. It will take me one to two hours to answer the questions.

Discomforts. The questions are not supposed to be difficult or disturbing to me. The only inconvenience is the time I will be giving up to be in the study.

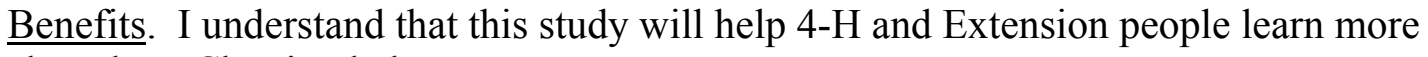
about how Charting helps teenagers.

Confidentiality. I have been promised that anything they learn about me in this study will be kept confidential. Anything that I complete will be given an identification number, instead of my name.

Voluntary Participation. I have been told that I do not have to be in this study. No one will be upset with me if I refuse to do this, or quit after I have started. I have been allowed to ask questions about the research, and all of my questional were answered. I will receive a copy of this form after I sign it.

I willingly agree to be in this study.

Signature of Participant

$\overline{\text { Signature of Investigator }}$ or

Investigator's Representative

$\overline{\text { Date }} \quad \overline{\text { Time }}$

Date

Time 


\section{APPENDIX B}

\section{Extended Objective Measure of Ego Identity Status} From Adams, Bennion, \& Huh. (1989). 


\section{Extended Objective Measure of Ego Identity Status}

Directions: Read each item and indicate to what degree it reflects your own thoughts and feelings. If a statement has more than one part, please indicate your reaction to the statement as a whole. On the line next to each item, write the letter that indicates your answer.

$$
\begin{aligned}
& 1=\text { strongly agree } \\
& 2=\text { moderately agree } \\
& 3=\text { agree } \\
& 4=\text { disagree } \\
& 5=\text { moderately disagree } \\
& 6=\text { strongly disagree }
\end{aligned}
$$

1. I haven't chosen the occupation I really want to get into, and I'm just working at whatever is available until something better comes along.

2. When it comes to religion I just haven't found anything that appeals and I don't really feel the need to look.

3. There's no single "life style" which appeals to me more than another.

4. Politics is something that I can never be too sure about because things change so fast. But I do think it's important to know what I can politically stand for and believe in.

5. I'm still trying to decide how capable I am as a person and what jobs will be right for me.

6. I don't give religion much thought and it doesn't bother me one way or the other.

7. I'm looking for an acceptable perspective for my own "life style" view, but I haven't really found it yet.

8. I haven't really considered politics. It just doesn't excite me much.

9. I might have thought about a lot of different jobs, but there's never really been any question since my parents said what they wanted.

10. A person's faith is unique to each individual. I've considered and reconsidered it myself and know what I can believe.

11. After considerable thought I've developed my own individual viewpoint of what is for me an ideal "life style" and don't believe anyone will be likely to change my perspective.

12. I guess I'm pretty much like my folks when it comes to politics. I follow what they do in terms of voting and such.

13. I'm really not interested in finding the right job, any job will do. I just seem to flow with what is available.

14. I'm not sure what religion means to me. I'd like to make up my mind but I'm not done looking yet.

15. My own views on a desirable life style were taught to me by my parents and I don't see any need to question what they taught me. 
16. There are so many different political parties and ideals. I can't decide which to follow until I figure it all out.

17. It took me a while to figure it out, but now I really know what I want for a career.

18. Religion is confusing to me right now. I keep changing my views on what is right and wrong for me.

19. In finding an acceptable viewpoint to life itself, I find myself engaging in a lot of discussions with others and some self exploration.

20. I've thought my political beliefs through and realize I can agree with some and not other aspects of what my parents believe.

21. My parents decided a long time ago what I should go into for employment and I'm following through with their plans.

22. I've gone through a period of serious questions about faith and can now say I understand what I believe in as an individual.

23. My parents' views on life are good enough for me, I don't need anything else.

24. I'm not sure about my political beliefs, but I'm trying to figure out what I can truly believe in.

25. It took me a long time to decide but now I know for sure what direction to move in for a career.

26. I attend the same church as my family has always attended. I've never really questioned why.

27. I guess I just kind of enjoy life in general, and I don't see myself living by any particular viewpoint to life.

28. I really have never been involved in politics enough to have made a firm stand one way or the other.

29. I just can't decide what to do for an occupation. There are so many that have possibilities.

30. I've never really questioned my religion. If it's right for my parents it must be right for me.

31. After a lot of self-examination I have established a very definite view on what my own life style will be.

32. My folks have always had their own political and moral beliefs about issues like abortion and mercy killing and I've always gone along accepting what they have. 


\section{APPENDIX C}

Interpersonal Reactivity Index

From Davis (1983). 


\section{$\underline{\text { Interpersonal Reactivity Index }}$}

Read each item carefully and write the number that best describes your feelings and thoughts next to each statement.

does not describe me well

5
4

3

2

describes me very well

1.___ I often have tender, concerned feelings for people less fortunate than me.

2.__ I sometimes find it difficult to see things from the "other guy's" point of view.

3.___ Sometimes I don't feel very sorry for other people when they are having problems.

4.___ In emergency situations, I feel apprehensive and ill-at-ease.

5.__ I try to look at everybody's side of a disagreement before I make a decision.

6._W When I see someone being taken advantage of, I feel kind of protective towards them.

7._ I sometimes feel helpless when I am in the middle of a very emotional situation.

8. I I sometimes try to understand my friends better by imagining how things look from their perspective.

9._ When I see someone get hurt, I tend to remain calm.

10.___ Other people's misfortunes do not usually disturb me a great deal.

11.__ If I'm sure I'm right about something, I don't waste much time listening to other people's arguments.

12._ Being in a tense emotional situation scares me.

13. When I see someone being treated unfairly, I sometimes don't feel very much pity for them.

14.__ I am usually pretty effective in dealing with emergencies.

15.__ I am often quite touched by things that I see happen.

16. I believe that there are two sides to every question and try to look at them both.

17._ I would describe myself as a pretty soft-hearted person.

18.__ I tend to lose control during emergencies.

19._When I'm upset at someone, I usually try to "put myself in his shoes" for a while.

20._When I see someone who badly needs help in an emergency, I go to pieces.

21.___ Before criticizing somebody, I try to imagine how I would feel if I were in their place. 


\section{APPENDIX D}

\section{Psychosocial Inventory of Ego Strengths}

From Markstrom et al. (1997).

Fidelity Subscale items only. 


\section{$\underline{\text { Psychosocial Inventory of Ego Strengths }}$}

\section{Fidelity Subscale}

\section{Directions:}

Read each item carefully and consider the degree to which it describes you. Write the number signifying your response on the line next to each item.

5

Describes Me

Very Well
4

3

2

\section{Does Not \\ Describe Me \\ Well}

6. I prefer to be free-floating without having to worry about commitments to other people or things.

10. I find that my opinions are frequently influenced by others.

18. When I make a commitment to something, I stick with it.

20. I don't pretend to be something that I'm not.

37. I believe in being true to myself and others.

41. I'm not really sure what I believe in.

48. I have trouble accepting a particular purpose or role in life.

53. I stand up for the people and causes that are important to me. 


\section{APPENDIX E}

Participation/Activities Measure Creative Activities Questions Only 
Please mark one for each activity that you have participated in THIS SCHOOL YEAR.

Clubs or groups:

$\begin{array}{ccc}\begin{array}{c}\text { School/Community } \\ \text { Does not offer }\end{array} & \begin{array}{c}\text { Did not } \\ \text { participate }\end{array} & \begin{array}{c}\text { Participated } \\ \text { Participated in as }\end{array} \\ \text { an } \\ \text { Officer/Leader }\end{array}$

Band, orchestra, chorus, choir, or other musical

group

Drama 